\title{
MEDIO SIGLO DE PRESENCIA DEL MOVIMIENTO ESTUDIANTIL EN LA UNIVERSIDAD PEDAGÓGICA NACIONAL 1957-1999
}

\begin{abstract}
Absalón Jiménez $B^{1}$
"La Juventud vive siempre en trance de heroísmo. Es desinteresada, es pura. No ha tenido tiempo aún de contaminarse. No se equivoca nunca en la elección de sus propios maestros. Ante los jóvenes no se hace méritos adulando o comprando. Hay que dejar que ellos mismos elijan sus maestros y directores, seguros que el acierto ha de coronar sus determinaciones. En adelante, sólo podrán ser maestros en la futura república universitaria los verdaderos constructores de almas, los creadores de verdad, de belleza y de bien,"
\end{abstract}

(Manifiesto de Córdoba, 1918)

\begin{abstract}
Reconstruir la historia de la universidad mediante las herramientas dadas por la historia política y social es trascender la historia oficial y normativa de lo que ha sido nuestra institución. Mediante el uso de estas herramientas logramos establecer el papel de los diferentes actores, que como el estudiantado, han colaborado, en diferentes coyunturas, a construir comunidad universitaria y un proyecto de nación. Desarrollar esta tarea representa a la vez un aporte para reconstruir nuestra cultura institucional y facilitar por este camino la reconstrucción de lo que se denomina comunidad universitaria. Una comunidad no puede surgir como proyecto colectivo si no conoce su historia, el pasado que la une, con una serie de diferencias y convergencias, lideradas por personas de carne y hueso que han dejado huella en las instituciones, en este caso en la Universidad Pedagógica Nacional.
\end{abstract}

Como más adelante lo observaremos, hablar de movimiento estudiantil en el ámbito nacional puede ser una osadía a excepción de la coyuntura que vivió el estudiantado durante el Frente Nacional. Para el caso colombiano se debe hablar más bien de coyunturas y actores estudiantiles que se han destacado en diferentes momentos en los que se han gestado luchas colectivas. La principal razón es que como movimiento social el estudiantado no acumula históricamente experiencia debido a que sufre una crisis generacional continua. Sin embargo, por sus manifestaciones y el papel que han jugado los estudiantes en las mismas instituciones se ha seguido hablando sin mayores complicaciones de movimiento estudiantil.

La Universidad Pedagógica Nacional, hasta hace unos pocos años, era reconocida como una de las universidades públicas más conservadoras de Bogotá; al parecer hablar de la presencia del estudiantado como movimiento en esta institución era algo impensable. Pero al reconstruir la historia de la universidad nos damos cuenta que en las diferentes coyunturas nacionales, a excepción de los últimos anos, el movimiento estudiantil de la Pedagógica ha respondido a una dinámica nacional, y que en buena medida ha aportado a la construcción de la historia del país. Como lo vamos a observar,

\footnotetext{
${ }^{1}$ Licenciado en Ciencias Sociales de la UPN y politólogo de la Pontificia Universidad Javeriana. En la actualidad elabora la tesis de la maestría de Historia de Colombia en la Universidad Nacional. Ha sido investigador del CIUP y en la actualidad es profesor catedrático del Departamento de Ciencias Sociales de Ia UPN.
} 
los estudiantes en la institución han tenido momentos importantes en los cuales sus demandas y movilizaciones han presionado decisiones en diferentes coyunturas, y a la vez han vivido momentos de crisis y de distanciamiento frente ala realidad nacional.

Desde 1918 con el movimiento estudiantil de la universidad de Córdoba en la Argentina una de las principales banderas de la lucha estudiantil es la autonomía universitaria, pero entendida dentro de una triada: universidad, sociedad y Estado, acompañada además de un tinte latinoamericanista y de lucha contra el imperialismo. El manifiesto emitido además establece como otros postulados: "el gogobierno estudiantil; libertad de cátedra, educación gratuita costeada por el Estado, elección de las autoridades universitarias con participación de todos los estamentos (profesores, estudiantes y egresados) y en general se busca la democratización de la universidad; todo ello sustentado sobre la base de la no intervención en la enseñanza superior de grupos de presión como la Iglesia, los sectores políticos y económicos ligados a la oligarquía y al imperialismo". ${ }^{2}$

Desde entonces, las anteriores banderas permearon las generaciones estudiantiles de la época en toda América latina, y Colombia no podía ser la excepción. Los estudiantes colombianos proclaman la Reforma en Medellín en 1922 yen Bogotá en 1924. En 1932 se publica el poema escrito por Germán Arciniegas: "El estudiante de la mesa redonda", donde exalta a los jóvenes a participar en la lucha de Latinoamérica. Posteriormente, entre los años 1935-39, se constituye la Federación de Estudiantes Colombianos (EEC) que juega un papel importante en la lucha antifascista oponiendo cierta resistencia a las dictaduras conservadoras y militares.

El legado de la Universidad de Córdoba incidió en la realidad política del país, en momentos en que tomaba fuerza un proyecto liberal y laico de universidad que, como la Universidad Nacional en 1935, toma un segundo impulso en el actual campus uniersitario. Un aspecto que asemeja la historia de la Universidad de Córdoba con la Universidad Pedagógica Nacional, es que la de Córdoba en Argentina era concebida como un proyecto conservador de universidad que fue fundada en el siglo XVII como bastión del clero y de la clase terrateniente hasta comienzos del siglo XX. Nuestra institución en su pasado inmediato que se remonta a la década de 1950, también nace como un proyecto conservador de universidad, apegada al clero y a ciertos valores tradicionales y verticales. Pero se debe anotar que no por ésto, los estudiantes desde su génesis dejaron de luchar conviniéndose en determinadas coyunturas en actores centrales de cienos cambios modernizantes en nuestra institución y el país.

\section{La salida de Radke, primer logro del movimiento estudiantil}

La profesora Franzisca Radke tuvo dos períodos de presencia en Colombia. En estos influyó con sus principios y preceptos nuestro aparato educativo nacional, coincidiendo con la presencia de dos gobiernos conservadores, quienes por principios ideológicos la seleccionaron, propusieron e impulsaron como directiva docente en las instalaciones de la Universidad Pedagógica Nacional ${ }^{3}$. Primero fue el gobierno de Miguel Abadía Méndez

\footnotetext{
${ }^{2}$ Carlos Arturo García, "El Movimiento estudiantil en Colombia. Década del sesenta", en Argumentos, Números 16-17, Bogotá, 1986. p. 189.

${ }^{3}$ El origen de la Universidad Pedagógica Nacional se remonta a 1917 cuando, en el marco del Primer Congreso Pedagógico Nacional y las normas educativas emanadas ese año, el gobierno ordena la construcción del Instituto Pedagógico Nacional para Señoritas. Dicho centro entraría a funcionar desde 1927 a 1951, cuando en un proceso de desmonte del proyecto liberal de la Escuela Normal Superior, el Instituto hereda la facción femenina de la Escuela Normal. Luego en 1955, la institución toma el nombre de Universidad Pedagógica Nacional Femenina; y finalmente en el año de 1962 pasa a convenirse en universidad mixta con el nombre que actualmente tiene: Universidad Pedagógica Nacional- Bogotá.
} 
(1926-1930); y luego el fracturado y conflictivo gobierno de Laureano Gómez Suárez (1950-1953).

Radke en su primer período, que duró ocho años (1927-1935), dirigió el Instituto Pedagógico Nacional, IPN, como antecedente directo de la universidad, inició su labor en un gobierno conservador, sosteniéndose durante todo un período de gobierno liberal convivialista ${ }^{4}$, como lo fue el de Enrique Olaya Herrera (1930-34), para salir por último en momentos en que se inicia el proyecto liberal de "La Revolución en Marcha" de Alfonso López Pumarejo en 1935, quien apoyó de manera irrestricta a la Escuela Normal Superior $^{5}$ como principal proyecto para la formación de maestros.

El segundo período de la profesora Radke (1952-1957), al igual que el ambiente que vivió el país durante estos, años fue más conflictivo. Si bien llegó en este periodo por iniciativa directa de Laureano Gómez, éste mismo desde el periódico El Siglo, en el año de 1957, patrocinaría su ataque y presionaría también su salida. La profesora Radke como extranjera tuvo que vivir en calidad de espectadora el golpe de Estado militar propinado a Laureano Gómez por el General Gustavo Rojas Pinilla, el 13 de junio de 1953. Producto de esta coyuntura, sumada a la relación que establece con el General Rojas y la consolidación del estudiantado como actor, se origina su salida en mayo de 1957.

Para algunos investigadores el ambivalente Movimiento Estudiantil Colombiano tiene como principal coyuntura de lucha los años que corresponden a la instauración y desarrollo del Frente Nacional, período establecido entre los años de 1958 a 1974 ${ }^{6}$. Para los investigadores de movimientos sociales en Colombia, como Mauricio Archila, es muy difícil hablar de movimiento estudiantil como movimiento social, existiendo más bien una serie de coyunturas de importancia en las que ha tomado fuerza el estudiantado como actor $^{7}$.

En el presente escrito se quiere dar a conocer que la génesis de lo que podríamos llamar movimiento estudiantil colombiano se ubica a finales del conflictivo período de Laureano Gómez. Es decir, desde el primer semestre de 1953 cuando se dan los primeros coqueteos al conformarse una organización nacional, para luego tomar forma como movimiento nacional en el régimen del General Rojas Pinilla a raíz de la masacre estudiantil del 8 y 9 de junio de 1954. El movimiento estudiantil obtuvo sus primeros logros

\footnotetext{
${ }^{4} \mathrm{Al}$ hablar de gobierno convivialista se refiere a la propuesta de Enrique Olaya Herrera como presidente liberal en 1930 a 1934 de "convivir" o compartir el poder con los conservadores, quienes jugaron un papel hegemónico en la política colombiana casi medio siglo, desde la década de 1880 con Rafael Núñez a la cabeza. El ambiente convivialista que se vivió en Colombia de 1930 a 1934 facilitó el sostenimiento de Franzisca Radke en el IPN. (El término "convivialista", es trabajado por Herbert Braun, Mataron a Gaitán, Bogotá, Norma, 1998, p. 45).

${ }^{5}$ Para estudiar de manera detenida la historia de la Normal Superior, como un proyecto liberal de formación de docentes en el que se encuentra una parte del origen de nuestra institución consultar el libro de Martha Cecilia Herrera y Carlos Low. Los intelectuales y el despertar cultural del siglo. El caso de la Escuela Normal Superior Una historia reciente y olvidada. Bogotá. UPN 1994.

${ }^{6}$ Para algunos investigadores como Francisco Leal Buitrago, el movimiento estudiantil nació y murió durante el Frente Nacional, el cual tuvo como punto máximo de desarrollo la consolidación de la Federación Universitaria Nacional, FUN, para finales de la década del sesenta y comienzos del setenta; ver "La frustración política de una generación y la formación del movimiento estudiantil", Revista Desarrollo y Sociedad, numero 6, julio de 1981, pág. 312.

${ }^{7}$ Mauricio Archila, Historia al final del milenio, Bogotá, Ed. Universidad Nacional, 1994, p.315 En su balance sobre Movimientos Sociales del Siglo XX da a conocer que "incluso se llega a poner en duda que se pueda hablar de la existencia del Movimiento Estudiantil en la historia contemporánea del país. Lo más cercano sería el movimiento dirigido por la Federación Universitaria Nacional de los años 60. En general se prefiere hablar de coyunturas estudiantiles o de luchas estudiantiles, más que de movimiento como tal". "La delimitación del accionar estudiantil se hace a partir de tres variables: demográfico-generacional, política y cultural. La primera se refiere a su carácter cíclico y transitorio tanto en términos de actores como de líderes. Se señala claramente que no es un movimiento social que acumule experiencia, puesto que esta continuamente rotando, con ciclos por lo general de un lustro. La segunda variable toca las expresiones políticas, especialmente de la izquierda, o al menos de aquellas comprometidas con la democracia. La tercera variable, está relacionada con la problemática cultural y juvenil.”
} 
en su papel de oposición y colaboración en la calda del régimen en mayo de 1957, junto a la salida de la profesora Radke dos semanas después ${ }^{8}$. Es así como el periódico El Siglo para inicios de 1953, da a conocer la organización de un Congreso Nacional Universitario que se realizaría del 8 al 12 de abril con participación de delegaciones regionales acompañadas de sus respectivas ponencias ${ }^{9}$. Se declara, además, que los anfitriones congregados en la Asociación Universitaria de Antioquia, AUDEA, desarrollarían un Congreso netamente católico ${ }^{10}$. A este evento en su momento la prensa laureanista le dio una relevancia importante:

De todas las manifestaciones colectivas que ha organizado la juventud universitaria es la de Medellín la más ambiciosa. Después de veintiún años de apatía gremial vuelven los universitarios colombianos. Significado profundo tiene el hecho de que sea la Asociación Universitaria de Antioquia, AUDEA, la gestora de este certamen nacional. La Asociación Universitaria de Colombia, que funciona en Bogotá entidad hermana de la primera, también ha aunado sus esfuerzos. Estas promociones del medio siglo han sentido nostalgia de las viejas organizaciones estudiantiles y por eso en el Congreso de Medellín va a resucitar la Federación Universitaria Colombiana, FUC ${ }^{11}$.

De manera efectiva el Congreso se realizó buscando como fin político la creación de la Federación Universitaria Colombiana, FUC, entidad encargada de velar por los intereses del estudiantado. Organización que nació marcada con los lineamientos laureanistas, enfocados a la educación y formación del perfecto católico, pero a la vez declarándose apolítica e independiente de los partidos tradicionales. En una de sus primeras manifestaciones respaldó totalmente el servicio militar obligatorio ${ }^{12}$.

Meses después de la realización de este primer Congreso Universitario, patrocinado por el proyecto laureanista de universidad, el 13 de junio de 1953, se daría el golpe militar del General Rojas Pinilla. Hecho que en el ámbito de las organizaciones estudiantiles originaría un cambio de orientación, pues tres semanas después del golpe, el día 3 de julio, la Universidad Nacional, su Consejo Académico y Directivo, le entregó un pergamino a Rojas Pinilla ofreciendo su pleno apoyo y adhesión a la obra del Jefe de Estado ${ }^{13}$.

Pese a esta adhesión hecha por una parte del sector universitario, se debe reconocer que los sectores urbanos fueron los más escépticos frente a las bondades democráticas que podría traer la presencia de un militar en el poder. Después de los acontecimientos narrados, de la génesis de este movimiento estudiantil, éste como actor colectivo se pierde del escenario por más de un año para reaparecer en el mes de junio de 1954, tras los graves hechos que afectaron al estudiantado colombiano, "marcando el comienzo del distanciamiento entre la opinión pública y Rojas, entre los sectores urbanos y los militares" 14 .

\footnotetext{
${ }^{8}$ En esta etapa de génesis y consolidación del movimiento estudiantil aun este no se había permeado de grandes propuestas ideológicas como el marxismo. Este instrumento político de la izquierda para estos años aún era un monopolio del Partido Comunista Colombiano, que medianamente lo estudiaba y lo difundía a sus cuadros. Las primeras organizaciones estudiantiles de la década del cincuenta se declaran católicas y apolíticas, independizándose del alzatismo conservador (sector dominado por el quindiano Gilberto Alzate Avendaño y opositor de Laureano) quien al parecer tuvo la intención de manipularlas.

9 El Siglo, 17 de febrero de 1953 . "Organizan un Congreso Nacional Universitario".

${ }^{10}$ El Siglo, 6 de abril de 1953. p. 5. "Netamente Católico será el Congreso Universitario".

${ }^{11}$ El Siglo, 6 de abril de 1953. "El Congreso Universitario". La cursiva es mía, debido a que de este proceso pero de manera particular de la Asociación Universitaria de Colombia, años después se desprendería la Unión Nacional de Estudiantes Colombianos UNEC, que presionarían de manera directa la salida de la Rectora de la Pedagógica en el año 1957.

${ }^{12}$ El Siglo, 4 de abril de 1953. p.19. "Congreso Universitario: concurren más de 100 delegados".

${ }^{13}$ El Siglo, 3 de julio. p. 2. "La universidad entregó un pergamino a Rojas Pinilla".

${ }^{14}$ Medófilo Medina. La Protesta urbana en Colombia en el Siglo XX, Aurora, 1994. Bogotá, p.91.
} 
El día 8 de junio de 1954 a las 3:40 de la tarde muere a causa de un tiro de fusil el estudiante Uriel Gutiérrez Restrepo en inmediaciones de la Universidad Nacional, en momentos que se estaba desarrollando una actividad cultural en el campus universitario. Al día siguiente en el centro de Bogotá, en la esquina de la cra. 7 con calle 13, cuando un grupo importante de sus compañeros protestaban por lo ocurrido, el saldo se elevó de manera despiadada, con la responsabilidad directa del Ejército, a un número de 13 muertos 40 heridos.

Estos acontecimientos fueron señalados por los hombres de Rojas como maquinados por el laureanismo, que junto al comunismo buscaba como fin la deslegitimación del régimen. El Ministro de Guerra, General Gustavo Berrio Muñoz, detiene por sospecha al ex rector Gerardo Molina, manifestando en una declaración:

"Ahí están los peces gordos...estoy convencido de que todo esto se debe a inconfesables propósitos extremistas encaminados a perjudicar el gobierno de las Fuerzas Armadas. Hemos recibido un copioso plebiscito en el cual el pueblo de todas la clases y condiciones, de uno y otro color político, expresan al señor Presidente su incondicional adhesión" ${ }^{15}$.

Estos graves acontecimientos originan la reorganización en la Federación de Estudiantes Colombianos, FEC, por medio de un comité provisional, el cual a la vez que rechaza estos hechos se declara categóricamente como una organización apolítica, pero que lucha por la democracia, la dignificación de la universidad, la libertad de pensamiento, de investigación y de expresión de ideas ${ }^{16}$. Se puede decir que desde este momento el estudiantado se convertiría en uno de los más importantes opositores del régimen de Rojas, para hacer luego su aporte en las jornadas de mayo de 1957 para el derrocamiento del militar.

En los meses de julio y agosto de 1954 se puede decir que se consolida la FEC, buscando como bases fundamentales: primera, la autonomía universitaria: académica, administrativa y financiera, operando sobre la base del autogobierno y entendida como una independencia sana del alma mater; segunda, las libertades universitarias: la investigación, la cátedra, el pensamiento estudiantil y su organización; y una orientación nacional de la universidad en la que el pueblo tenga acceso ${ }^{17}$. En términos generales los estudiantes agremiados en la Federación de Estudiantes Colombianos, FEC, lucharon por el "restablecimiento" del proyecto liberal de universidad y propusieron, ya en este ambiente de distanciamiento con Rojas, restablecer la ley 68 de 1935, desvirtuada y derogada por providencias sucesivas desde el año $1946^{18}$.

Un año después de este proceso en un elocuente discurso en el mes de junio de 1955 el presidente de la FEC, el estudiante Crispín Villazón de Armas, daría a conocer la consolidación del movimiento y la necesidad de lograr su principal objetivo, la autonomía universitaria, mediante las siguientes palabras:

¿A qué tantos aspavientos? Se cree que nosotros pedimos una universidad utópica, algo del otro mundo. Lo que nosotros pedimos es cosa vieja en las universidades modernas. Los estudiantes no piden demasiado sino que se les niega todo. Los estudiantes no son revolucionarios en tanto no se impide el lógico cumplimiento de las leyes evolutivas. Los

\footnotetext{
${ }_{16}^{15}$ El Tiempo, 11 de junio de 1954. p. 18. "Prosiguen investigaciones sobre los sucesos del miércoles".

${ }^{16}$ El Tiempo, 11 de junio de 1954. p. 21. "Hablan los estudiantes". A esta declaración hecha en su grueso por estudiantes de la Universidad Nacional, desde el día lunes 14 de junio se registran adhesiones de otras universidades como la de la Asociación boyacense de Estudiantes, organización que se reunió y sacó una resolución en la cual condena los atentados y exige la investigación a los culpables, hace un llamado para que se fortalezca la FEC y exige, por último, la Autonomía Universitaria.

${ }^{17}$ El Tiempo, 14 de agosto de 1954. p. 10. "La Federación Estudiantil expone la Reforma Universitaria".

${ }^{18}$ El Tiempo, 16 de agosto de 1954. "La reforma universitaria" 
estudiantes no son locos sino se les trata como tales. Lo peor es el miedo que se le tiene a la palabra "Reforma". Nosotros no se lo tenemos porque aspiramos a una reforma limpia. Creemos que la reforma supone inmediatamente la autonomía plena. ${ }^{19}$

Se nota así como la organización estudiantil colombiana tiene su principal momento de consolidación en el régimen militar de Rojas. En este tomaría fuerza la FEC (por encima de la FUC, organización estudiantil antioqueña), adhiriéndose también una organización estudiantil femenina denominada la Asociación Femenina Estudiantil, Casa para las Residencias AFE en el mes de marzo de 1955. En los Últimos meses de su mandato, la FEC supera una etapa de lógico centralismo dado en Bogotá, para recibir una serie de adhesiones regionales y adquiere un verdadero sentido nacional. Se registra así la creación de Federaciones Regionales, tales como la AUDA de Antioquia, la Federación de Estudiantes de Bolívar, la filial de Barranquilla y la Federación de estudiantes del Cauca $^{20}$.

La principal razón de la derrota de Rojas en las jornadas de mayo de 1957 fue la movilización urbana, el cierre del comercio, el cese de actividades laborales y los paros de tipo patronal. En tal movilización el estudiantado jugó un papel importante que posteriormente fue reconocido por los partidos tradicionales y la junta militar que sucedió a Rojas.

En estos críticos momentos del gobierno de Rojas, la Universidad Pedagógica Nacional Femenina comenzaba a vivir una serie de conflictos que también harían parte de la historia política y social del país. Coyuntura investigada de manera profunda por Juan Carlos Garzón, en un trabajo de monografía del departamento de sociales en el cual concluyó que:

En la salida de la Dra. Radke de la Universidad Pedagógica Femenina saltan a la vista dos razones fundamentales. De una parte la universidad en cabeza de la señora Radke había intentado otorgar en 1956 el Doctorado "Honoris Causa" en Ciencias Sociales a Doña Carola Correa de Rojas, esposa del General Rojas Pinilla, cuyo gobierno había caído doce días antes de su renuncia a la Rectoría, esa parece ser parte de la cuenta de cobro de los huelguistas. De otro lado a juzgar por las solicitudes de las estudiantes y profesores de la Universidad. La mano fuerte que habla empleado la Señora Radke en el proceso de consolidación de la institución, generó la resistencia de algunos sectores que reclamaban mayor participación del personal colombiano en la dirección del centro educativo ${ }^{21}$.

Por nuestra parte, se puede concluir que el trasfondo político de la salida de Radke del país en junio de 1957 es la suma de tres elementos: la crisis y la caída del General Rojas Pinilla, la consolidación del movimiento estudiantil, y la presión de los conservadores laureanistas que desde el diario El Siglo le dieron la estocada final.

En la consolidación del movimiento estudiantil que se enfrentó a Radke tuvo particular importancia el papel que jugó el profesor Carlos Páez Pérez, de la Facultad de Ciencias Biológicas y Químicas, quien a su vez dictaba clase en la Universidad Nacional, persona supremamente culta que había estudiado en Francia. Por su carisma el profesor Páez Pérez tenía la posibilidad de aglutinar a su alrededor alumnas de las diferentes facultades,

\footnotetext{
${ }^{19}$ El Tiempo, 12 de junio de 1955.p. 2. "El Debate sobre la reforma universitaria: autonomía y nuevos métodos".

${ }^{20}$ El Tiempo, 26 de noviembre de 1956. "La FEC extiende su organización".

${ }^{21}$ Juan Carlos Garzón Barreto, Orígenes y Consolidación de la UPNF. 1955-1962, Monografía de Grado en Licenciatura de Ciencias Sociales en la UPN 1997, p.75. 
a quienes hacía ver la importancia de los movimientos estudiantiles y la necesidad de cuestionar la situación de la universidad ${ }^{22}$.

Este profesor relacionó a las estudiantes de la Pedagógica con dirigentes del movimiento estudiantil de la Universidad Nacional agremiados en la UNEC (Unión Nacional de Estudiantes Colombianos), particularmente con Diego Augusto Leyva Samper, Antonio Larrota y Guido Herrera. La profesora Mercedes González Lanza manifestó que poco a poco y sin ningún afán se fue consolidando el "Comité de Huelga". "Una mañana me llamaron a reunión y posteriormente continuamos encontrándonos en el espacio de las residencias estudiantiles SENDAS"23.

El 10 de mayo de 1957 Rojas Pinilla se ve obligado a entregar el poder a una junta militar. Pocos días después el movimiento estudiantil robustecido tendría como blanco particular de ataque la rectoría de Franzisca Radke en la Pedagógica Femenina, a quien relacionaron políticamente con lo que tiempo atrás se había comenzado a de nominar "rojaspinillismo"24. Es así como, para el 21 de mayo, un grupo de estudiantes después de un proceso de agitación interna presentaron el siguiente pliego de peticiones:

Primero. Solicitan el cambio de la Señora Rectora de la Universidad, Franziska Radke, por una figura ciudadana cuya capacidad constituya una garantía en la solución de los problemas de dicha universidad.

Segundo. Reorganización del sistema que la Sra. Radke ha implantado tanto en el orden pedagógico como científico y disciplinario.

Tercero. Revisión de títulos académicos que tengan los profesores que actualmente colaboran con la Señora Radke, muchos de ellos de la misma nacionalidad.

Cuarto. Corregir el mal tratamiento que algunos profesores extranjeros dan a las alumnas durante las clases con criterio dictatorial.

Quinto. Igualdad de privilegios para catedráticos colombianos y extranjeros ya que estos últimos tienen privilegios especiales.

Sexto. Asignación de becas de conformidad con el plan técnico.

Séptimo. Modificar el ambiente de humillación de las alumnas dado por la Rectora, otorgar la libertad de presentar las justas reclamaciones de las alumnas a la Rectora y las directivas.

Octavo. Aumento de presupuesto de la universidad con el objeto de organizar laboratorios de Ciencias Naturales, Química, Física, Fonética y una Biblioteca.

Noveno. Mejoramiento de las condiciones económicas tanto del profesorado universitario como de los institutos anexos.

Décimo. Informar las determinaciones que toma la universidad a fin de darlas a conocer al alumnado para evitar arbitrariedades.

Undécimo. Imparcialidad en la distribución en los servicios de la universidad.

Duodécimo. Revisión fundamental del programa universitario existente con criterio moderno.

\footnotetext{
${ }^{22}$ Ibid. 77

${ }^{23}$ Entrevista de Juan Carlos Garzón con Mercedes González. Mayo de 1997.

${ }^{24}$ Cesar Augusto Ayala Diago. Resistencia y aposición al establecimiento del Frente Nacional. Los orígenes de la Alianza Nacional Popular (ANAPO). Colombia 1953-1964. Colciencias, 1996. cap. 1. El rojaspinillismo tiene su origen en enero de 1955, cuando el General Rojas Pinilla anuncio que durante su gobierno no levantaría el Estado de Sitio. Afirmaciones que produjeron malestar en el seno de colectividades políticas tradicionales. Un columnista de El tiempo llamó a formar un "Frente Democrático", que vigilara la libertad. El régimen recibió de inmediato el respaldo de algunos dirigentes liberales reunidos en un organismo denominado "Alianza popular Pro- Binomio Pueblo Ejército por pan, techo, salud y alfabeto para todos los colombianos". En su primera declaración respaldan al presidente militar y al Estado de Sitio como sinónimo de lucha contra la oligarquía. Esta dio origen al Movimiento de Acción Nacional (MAN), que logró tener una vida esporádica de un mes (enero de 1955), en la cual estableció una plataforma ideológica. Según el documento, entre las bases de su programa se desataca la lucha antimonopolios, la defensa sindical, el sentido nacionalista del Estado sin ningún matiz de partido y se subraya su carácter suprapartidista. En la consolidación del MAN se tiene que establecer el origen del rojaspinillismo que en la década del sesenta desembocaría en la consolidación de la Alianza Nacional Popular ANAPO.
} 
Decimotercero. Estímulo de la investigación científica tanto para el profesorado como para las alumnas de la institución ${ }^{25}$.

Como observamos, al menos cinco de los puntos de demanda hechos por las estudiantes tienen que ver con una actitud de autoritarismo y verticalidad asumida por la rectora en la toma de decisiones, además de la discriminación de que eran objeto tanto profesores como estudiantes por parte de su administración. La profesora Mercedes González describió la situación de la universidad en los siguientes términos:

Fundamentalmente era como ese autoritarismo de la Dra. Radke, y del grupo de dirigentes de la universidad que la acompañaban, pues obedecían a una serie de órdenes. Iban a manifestaciones políticas de respaldo al gobierno, condecoraron a la Señora Carola de Rojas, no sé si ella lo recibió, pero eso demostraba como esa tendencia conservadora de la universidad. Había demasiada rigidez, demasiado autoritarismo. ${ }^{26}$.

A la semana siguiente de estos acontecimientos vendría la arremetida del sector laureanista que desde el diario El Siglo terminaría de colocar a la opinión pública en contra de Radke. Laureano Gómez, una vez sufre el golpe de Estado por parte de Rojas Pinilla en junio de 1953, nunca perdonó estos hechos declarándose desde entonces como enemigo del rojaspinillismo. Una vez se instalan las bases para el Frente Nacional en las que Laureano jugó un papel central, sectores que se vieron comprometidos políticamente con el régimen militar quedaron en incómoda posición una vez Rojas entrega el poder. Paradójicamente el sector conservador laureanista, que años atrás había presionado la llegada de Radke al país, es el que presiona externamente su salida de la universidad ${ }^{27}$. El periódico EI Siglo, el 30 de mayo de 1957, daría a conocer el siguiente artículo:

En la Pedagógica Femenina un grupo de Ex - alumnas de la Universidad Pedagógica Nacional Femenina, sostuvo una larga reunión, al final de la cual firmaron una nota dirigida al Señor Ministro, en la que hacen numerosos cargos a la rectora Franzisca Radke, dando cuentas de las arbitrariedades y despotismos, como también habla de que ha llegado a tal extremo que sin tener en cuenta la idoneidad de los profesores del país y de algunos profesores extranjeros, se les reemplaza con táctica y oportunismo de acuerdo con las circunstancia nacionales ${ }^{28}$.

Al día siguiente, 31 de mayo, el mismo diario daría a conocer una extensa carta en la que las huelguistas manifiestan no concurrir a clases hasta tanto no sea cambiada la Sra. Radke $^{29}$. Por su parte, el Ministro de Educación solicitó a las huelguistas permanecer en las inmediaciones de la planta física hasta llegar a una solución, la cual se dio el sábado 1 de junio. El periódico El Siglo, que fue el medio de comunicación que estuvo más atento a este proceso, dio a conocer:

\footnotetext{
25 El Tiempo, 22 de mayo de 1957. Esta acta fue firmada por un Comité de estudiantes integrado por alumnas de diferentes facultades, así: por la Facultad de Física y matemática: Leonor Castilla Guerra y Leonor Avella Díaz. Por la Facultad de Química y Biología: Inés Triana Garay, Mery Ruiz González. Hilda Hernández García y Azucena Gómez Vergara. Por la Facultad de Ciencias Sociales y Económicas: Elvira Guzmán Barreto María Cristina Cayón Bonivento. Por la Facultad de Fonología e Idiomas: Beatriz Laverde Toro, Fabiola Carrasquilla y Helena Fajardo Obando. Por la Facultad de Psicología y Ciencias de la Educación: Inés Vanegas Sierra y María Helena Arango Londoño. Citado por Juan Carlos Garzón. Op., Cit. p. 79

${ }^{26}$ Entrevista de Juan Carlos Garzón con Mercedes González, mayo de 1997. Op. Cit p. 79.

${ }^{27}$ Entrevista de Absalón Jiménez con Mercedes González. Septiembre de 1999.

${ }^{28}$ El Siglo, 30 de mayo de 1957. Citado por Juan Carlos Garzón. Op. Cit . p. 80.

${ }^{29}$ Esta solicitud es firmada por un Comité de huelga en el que aparecen los nombres de la profesora: Mercedes González Lanza, Hilda Hernández, Margarita Reyes, Helena Fajardo Obando, Flor Lila García e Inés Triana Garay. 
Hoy presenta renuncia la Directora de la Pedagógica, dijo el Ministro Carbonell. Por intermedio de Monseñor Elorza, Miembro del Consejo Directivo de la Universidad Pedagógica Femenina. La Directora de la Universidad. Señora Franziska Radke me anunció que hoy presentaría su renuncia.

Los Universitarios hombres y mujeres encontraron cerradas las puertas de acceso y después de proferir una serie de gritos de protesta, éstas le fueron abiertas, mientras tanto las profesoras y personal que se encontraban dentro de la edificación de tres pisos cerraron las aulas y salones, replegándose a la clausura o habitaciones particulares. Las huelguistas acompañadas de sus colegas, a quienes fueron a invitar hasta las respectivas universidades invadieron el edificio y se dedicaron a colocar sobre muros letreros irreverentes con tiza verde y blanca. Uno decía cerca a Cristo este letrero: "Dios aplaude nada con ellos"30.

Pese a que días después se gestó un movimiento de apoyo a Radke, desde el Instituto Pedagógico Nacional, por parte de las estudiantes de secundaria y algunas ex alumnas de la Rectora, esta reacción fue tardía y el objetivo del primer movimiento estudiantil que se gesta en la Pedagógica había triunfado, claro esta que con un importante apoyo externo. Así termina el segundo período de Radke en Colombia, dejando una importante huella en la educación.

No obstante este último conflicto, se debe reconocer que Radke consolidó dos instituciones importantes en la historia del país en el siglo XX que tienen que ver con la formación de docentes: el Instituto Pedagógico Nacional en los años treinta, y la Universidad Pedagógica Nacional en los años cincuenta. Además realzó el papel de la mujer y la incrusta en el espacio laboral docente; y lo más importante, fomentó los principios de la Escuela Activa en Colombia durante la primera mitad del siglo.

\section{El Movimiento estudiantil de los años sesenta}

En la década de los años sesenta el movimiento estudiantil supera su etapa de consolidación y atraviesa a la vez su mejor momento. El Movimiento Estudiantil del Frente Nacional tendría un antecedente directo en la FUC, junto a su rival la FEC, nacida como consecuencia de los hechos de junio de 1954 para luego enfrentar a la dictadura. Dichas organizaciones se ponen de acuerdo para la celebración del Primer Congreso Nacional de Estudiantes que se realizó en el mes de junio de 1957. En este acto en medio de un enfrentamiento ideológico entre la EEC y la FUC se retira esta última. De este Congreso surgió la Unión Nacional de Estudiantes Colombianos, UNEC, liderada por Antonio Larrota, la que rechazó cualquier herencia de organizaciones anteriores y proclamó como principios la libertad de enseñanza y de investigación científica, la autonomía universitaria y la oposición al militarismo. Se planeó como una organización gremial estudiantil de carácter nacional $^{31}$.

El movimiento estudiantil que se consolida durante el Frente Nacional incidirá de manera directa en la vida de la Universidad Pedagógica Nacional. La UNEC tendría uno de sus primeros triunfos en la Pedagógica con la salida de Franzisca Radke. Pero ya en el período del Frente Nacional la organización siguió reflejando políticamente lo que se vivía en el resto del país. En 1959, como lo narra Francisco Leal Buitrago, la actividad política estudiantil se inició con la aparición del Movimiento Obrero Estudiantil Campesino Colombiano, MOEC, dirigido de nuevo por Antonio Larrota. En los años sesenta el Movimiento Revolucionario Liberal, MRL, hizo presencia dentro de las organizaciones

\footnotetext{
${ }^{30}$ El Siglo, 1 de junio de 1957. Citado por Juan Carlos Garzón. Op. Cit p. 80.

${ }^{31}$ Francisco Leal Buitrago. Op. Cit. p. 305.

Digitalizado por RED ACADEMICA
} 
estudiantiles junto a las Juventudes Comunistas Colombianas con el fin de buscar una base de apoyo para luchar contra el acuerdo bipartidista de reparto burocrático del poder. Paralelamente comenzaron a difundirse manifiestos y comunicados de nuevos grupos como la Unión de Juventudes Comunistas de Colombia, indicadores del proceso de radicalización del liderazgo estudiantil ${ }^{32}$. Se inicia así un importante proceso en que el estudiantado poco a poco se independizaría del monopolio bipartidista que hasta los años cincuenta había ejercido la clase política tradicional sobre las organizaciones estudiantiles ${ }^{33}$.

El año de 1960 es importante porque el estudiantado hizo uso de un nuevo medio de expresión política: la huelga. Esta herramienta es usada en la ciudad de Bogotá por parte de los estudiantes de la Nacional para presionar la salida del rector ${ }^{34}$, logrando inclusive una reunión con el Presidente de la República y la conformación de una Comisión de reforma universitaria. Esta táctica se extendería a otras universidades del país ${ }^{35}$. Empieza así la época dorada del movimiento estudiantil que llega hasta el año de 1964 cuando los estudiantes en el caso de la UIS logran la solidaridad de toda la ciudadanía de Bucaramanga en torno a sus banderas de lucha ${ }^{36}$.

En 1961 se dan los primeros pasos de reorganizar con una visión gremialista al estudiantado en torno a la bandera de la autonomía universitaria. Luego, en mayo de 1962, se suma otro antecedente cuando 6.000 estudiantes de las universidades Nacional y Libre se lanzan a un paro de solidaridad con los de la Pedagógica de Tunja después de que su claustro fue objeto de abusos por un grupo de suboficiales de la guarnición boyacense a los cuales los estudiantes pedían sancionar por parte de sus superiores ${ }^{37}$. Sin embargo, es hasta septiembre de 1963, en momentos de acaloradas movilizaciones y graves hechos como la muerte de Antonio Larrota, que se dan los primeros pasos para la creación de una nueva organización estudiantil nacional.

En este momento no solamente había una línea estudiantil gremialista sino se sumaría otra: la política, que jalaría a un importante sector juvenil a la izquierda. En este mes se da un Congreso Distrital Universitario en el cual participa la Pedagógica Nacional ${ }^{38}$. Dicho evento sirvió de base para que en el mes de noviembre se reuniera un Congreso Nacional que, con la delegación de 17 universidades del país, creó la Federación Universitaria Nacional, FUN. De esta organización uno de sus primeros presidentes fue el entonces

\footnotetext{
${ }^{32}$ Ibid. p. 306.

${ }^{33}$ Para la década de los años sesenta el marxismo dejó de ser monopolio exclusivo del Partido Comunista, pasando su socialización a la cátedra universitaria. Se crean nuevas carreras como sociología y antropología que permiten su lectura. La revolución cubana también incidiría en el cambio de orientación ideológica de la juventud de los años sesenta. En esta década se comienza a dar una importante ruptura, pues a los sectores de izquierda se les deja la bandera de la autonomía universitaria asociada a la lucha subversiva, otros sectores estudiantiles, entre ellos los de la gran mayoría de universidades privadas lucharían por la bandera de la calidad académica.
}

\footnotetext{
${ }^{34}$ EL Siglo, 19 de abril de 1960. "El mal de la universidad está en la cabeza". En este artículo se evidencia la posición de 6.500 estudiantes que se declaran en huelga solicitando inicialmente la renuncia del profesor de arquitectura Pablo Lanzzette. Para el 27 de agosto del mismo año los estudiantes en medio de otra huelga estudiantil se declaran en Asamblea Permanente y piden la renuncia del Rector de la Nacional Mario Laserna, objetivo que logran el mismo 27 de agosto de 1960. Ver también el periódico el Tiempo 26 y 27 de agosto de 1960 .

${ }^{35}$ El Siglo. 12 de enero de 1960. Por medio de una táctica similar los estudiantes de la Universidad de Cartagena logran la renuncia del entonces rector Alberto Fernández Baena.

${ }^{36}$ El Tiempo, 25 de junio de 1964. "Apoyo de la ciudadanía a la UIS”. Se declara normalidad en lo que se convirtió en un paro cívico. Se logra que el Ministro de Educación viaje a Bucaramanga.

${ }^{37}$ EL Siglo, mayo 31 de 1962.

${ }^{38}$ En el Congreso de septiembre de 1963, según Francisco Leal Buitrago, participarían además las universidades Nacional, Gran Colombia, Distrital, Externado de Derecho, Libre, América, Piloto, la Escuela de Administración Pública y dos observadores de la Universidad Inca y Jorge Tadeo Lozano.
} 
estudiante de sociología Galo Armando Burbano López, quien en la década del noventa sería rector de la Universidad Pedagógica Nacional. Bajo, el liderazgo de este estudiante se jalonarían huelgas de carácter nacional universitario ${ }^{39}$, que con una visión gremialista se solidarizan con las universidades de Tunja, Antioquia ${ }^{40}$ y Cartagena ${ }^{41}$. Además en este período en la FUN ocurren grandes hechos como la asonada que lideran los estudiantes de la Nacional en contra de la candidatura de Carlos Lleras Restrepo a la presidencia de la República ${ }^{42}$, quien años después cobraría esta irreverencia. También la FUN dió apoyo irrestricto a las iniciativas del padre Camilo Torres Restrepo en su etapa de profesor de la Nacional y en su propuesta de cambio revolucionado buscando consolidar el Frente Unido $^{43}$.

\section{La Comisión de Evaluación Institucional de 1967. Una presión del estudiantado}

\section{Como lo narra Alfredo Molano en Contribución a una biografía de la Universidad}

Pedagógica Nacional, en el mes de agosto de 1967 considerando el crecimiento de la institución, el Consejo Directivo nombró una Comisión de Evaluación compuesta por tres personas externas a la institución. Esta Comisión estuvo integrada por un representante del Ministerio de Educación, Doctor Aurelio Céspedes, y de dos decanos de las otras dos facultades de educación de importancia en el país, instituciones que acompañarían a la universidad en posteriores procesos años después. Nos referimos al Decano de la Facultad de Educación de la Universidad de Antioquia, Guillermo Vélez, y al Decano de la Facultad de Educación de la Universidad del Valle, José Ángel. A esta Comisión varios de los antiguos profesores la recuerdan como la Comisión Céspedes-Vélez-Ángel.

Según se desprende del acta, la Comisión fue sugerida por el representante de la Curia Monseñor Franco Arango, como un medio para atender las presiones del Movimiento Estudiantil que ya había ganado presencia nacional. Entre otras demandas los estudiantes solicitaban la necesidad de elevar el nivel académico de la Universidad ${ }^{44}$.

Esto en momentos en que la dirección de la institución estaba a cargo de Irene Jara de Solórzano (1959-1968), quien en buena medida encarnaba la estirpe tradicional de una universidad femenina basada en los principios de la escuela activa, junto a toda la sombra de mediados de siglo dejada por Radke.

En su intervención ante el Consejo Directivo, Monseñor Franco Arango expresa que: "Los estudiantes han lanzado acusaciones contra la rectora que llega al Consejo porque ella representa el Consejo. La corporación debe tomar las decisiones que son de su competencia. Hay interés del Consejo en que se conozca la realidad y que sea analizada por personas autorizadas científica, moral e intelectualmente, para superar las diferencias

\footnotetext{
${ }^{39}$ El Siglo, 2 de junio de 1964. La FUN como una de sus primera acciones se traza la realización de un paro nacional universitario de 48 horas que compromete a 18 universidades. El paro que se gesta desde Bogotá se solidariza con la situación de universidades en conflicto como la UIS y la del Atlántico.

${ }^{40}$ El Siglo, 24 de julio de 1965.

${ }^{41}$ El Siglo, 3 de agosto de 1965.

${ }^{42}$ El Siglo, 8 de noviembre 1964. "Las piedras, formol y los gritos, armas ofensivas del estudiantado contra Lleras en la Nacional". El candidato presidencial fue retenido durante dos horas en la facultad de derecho por parte de los estudiantes quienes rechazaron un supuesto apoyo irrestricto de la universidad a su candidatura. Años después este hecho traería nefastas consecuencias como la cancelación de la FUN por parte del mismo Lleras y la Reforma Universitaria de 1968, lesiva para la autonomía universitaria.

${ }^{43}$ El Siglo, 23 de mayo de 1965. El padre Camilo Torres dijo ayer que el país está reclamando una revolución y que para hacerla es necesario formar un frente común de todos los movimientos revolucionarios", ésto en homenaje que le ofreció la Federación Universitaria Nacional.

${ }^{44}$ Acta del Consejo Directivo, No. 12 de 1967. Archivo Rectoría UPN. Citado por Alfredo Molano en Contribución a una biografía de la Universidad Pedagógica Nacional. Documento mecanografiado. Centro de Documentación de la UPN. p. 65. 
señaladas". Para Monseñor, la carta en que los estudiantes resumían sus quejas era la radiografía que los condena, y agrega que: "el siguiente paso debe ser la investigación de los estudiantes. Cuando se conozcan las conclusiones de la Comisión debe pasarse a buscar los medios para erradicar el fenómeno subversivo que se ve en el movimiento de los estudiantes" ${ }^{45}$.

Como se puede concluir, de manera directa o indirecta, el estudiantado después de una serie de grandes cambios en la década de los años sesenta presionaría para el establecimiento de la primera Comisión de Evaluación Externa que tendría la institución. Comisión que realizó grandes críticas a la Universidad Pedagógica. La primera tiene que ver con el carácter administrativo de la misma, ante todo por la estructura de poder. El informe señala la excesiva centralización administrativa en la rectoría y la débil delegación de funciones, para proponer luego cambios administrativos que afecten todos los organismos directivos. En varios de sus apartes más importantes la Comisión recomienda:

Otorgar al Consejo Directivo el cambio de nombre y categoría, estableciendo las funciones necesarias para fijar la política administrativa y financiera de la universidad, transferir la competencia del Consejo Directivo al Consejo Académico, y las de éste al Consejo de Facultad, donde decanos y profesores discutan la política académica; cambiar el sistema de elecciones estudiantiles en el sentido de que el representante de este estamento sea elegido por los estudiantes, previa fijación de criterios y procedimientos de elección del Consejo Directivo ${ }^{46}$.

Para la Comisión, la Rectoría debe dar mayor autonomía a los decanos al tiempo que promueva su participación en la elaboración y ejecución del presupuesto y en la dirección de la docencia. En el ámbito administrativo, el informe diagnostica una centralización que entorpece las funciones de la Secretaría Administrativa para ejercer el presupuesto. Además, como este se gasta en más del 50\% en actividades no universitarias, recomienda que el presupuesto se dedique en forma efectiva a la universidad ${ }^{47}$.

En el ámbito académico se promulga la creación de un Comité Curricular que haga una evaluación y una reestructuración total de los programas con el objetivo de unificar e integrar las materias, descongelando y flexibilizando el currículo; además, exige un mayor aporte para la Facultad de Educación Física descuidada por años según su percepción. La Comisión en términos generales recoge parte de las aspiraciones del informe Atcon que buscan modernizar las instituciones universitarias mediante un perfil norteamericano.

Por último, la Comisión a nivel de los organismos estudiantiles se percató de que las directivas de la universidad no veían con buenos ojos la formación de Federaciones o Consejos Estudiantiles, y recomendó deliberar sobre estos problemas y necesidades ${ }^{48}$.

\section{La radicalización del movimiento}

El movimiento estudiantil de la Pedagógica, además de acompañar el proceso nacional, en esta coyuntura vivía sus propias batallas. Como lo observamos, el estudiantado fue el actor que presionó la primera Comisión de Evaluación con pares externos que tuvo la universidad, la cual concluyó con una serie de críticas por el bajo nivel de sus programas y por su centralización administrativa en manos de la rectoría de Irene Jara de

\footnotetext{
${ }^{45}$ Acta del Consejo Directivo. Número 12 de 1967. Archivo de Rectoría UPN.

${ }^{46}$ Informe Céspedes-Vásquez- Ángel. Archivo Rectoría. UPN. Este documento fue discutido en un seminario profesoral en 1968.

${ }^{47}$ Ibid. P .3.

${ }^{48}$ Alfredo Molano, Op. Cit. p.69

Digitalizado por RED ACADEMICA
} 
Solórzano. La lucha fuerte del estudiantado, que se da en el año de 1967, se debe ubicar en momentos en que la institución, en un gran porcentaje, sigue teniendo un predominio femenino. La entrada de los hombres se permite inicialmente en las carreras, llamadas en ese entonces facultades nocturnas de educación, las cuales son cerradas en noviembre de 1964, hecho que se convierte indirectamente en un golpe desestabilizador del estudiantado $^{49}$. Para el mes de mayo de 1966 la Facultad de Educación Física entraría en huelga por el descuido y desarraigo frente a la institución, la cual al parecer no había dado la importancia que merecía esta carrera dentro de la misma ${ }^{50}$.

Pero en realidad, es el problema de la calidad académica de las facultades de educación lo que mueve al estudiantado de la Pedagógica en 1967, denuncia que se hace evidente hacía comienzos del mes de julio. Entre otros puntos demandan los siguientes: “a) el incumplimiento del decreto 2118 de 1962, que permitió la entrada al sector masculino a la universidad, punto en el que la institución hasta ese año seguía mostrándose renuente; b) supresión de las facultades nocturnas, la cual permitía la presencia de estudiantes que laboraban de día, en su mayoría hombres; c) discriminación y persecución para aquellos que no están de acuerdo con los sistemas arcaicos de enseñanza; d) persecución a profesores por la misma razón; e) presión a profesores que hacen observaciones en beneficio de la universidad; f) desórdenes de programas y nula planeación; g) marginación de la universidad del incremento de la educación a escala nacional"51.

El segundo semestre de ese año fue agitado, pues en tanto que se conformó la Comisión Vásquez - Céspedes- Ángel, el estudiantado seguiría presionando para que los anteriores puntos fueran tenidos en cuenta. La discusión, al igual que diez años antes en los tiempos de Radke tenía una relevancia nacional colocando en entredicho, en esta ocasión, el panorama educativo. Escuchemos el editorial de El Siglo:

\begin{abstract}
¿Qué sucede con la educación? Panorama de encrucijada educativa. No hay programa definido ni una política educativa, prima el arbitrio personal y prospectos improvisados, extranjerizantes y caducos. Existe una honda crisis del sistema educativo y no hay iniciativa alguna. Un ejemplo del caos y retroceso es el que ha venido agitando la opinión pública en relación con la UPN en donde los estudiantes vienen clamando desde hace tiempo porque se les mejore el nivel académico, se actualicen los estudios y se releven las directivas". Según los estudiantes: "En la Pedagógica se dilapida el dinero del Estado, acabaron los estudios de capacitación para el profesorado; clausuraron las facultades nocturnas; se sacan licenciados al vapor; es una fábrica de títulos sin espíritu, sin afán de servicios y sin deseo de superación ${ }^{52}$.
\end{abstract}

Por su parte, los sectores oficiales de la institución señalaron ante las demandas de los estudiantes, que este movimiento no trataba de mejorar el nivel académico de la institución sino más bien buscaba sembrar el desconcierto para apoderase de la Pedagógica, desde la rectoría hasta las cátedras. Se recriminó que este grupo de estudiantes estaba interesado en la agitación y en la política, no propiamente investigativa. Para un grupo de profesores: "si en la Nacional en ese año se había logrado disfrazar objetivos políticos en un ambiente de estudio, ahora la presión se ejerce hacía la Pedagógica de la Avenida Chile a la que quieren convertir en otro centro más de agitación contra el país"53

\footnotetext{
${ }^{49}$ El Siglo, 13 de noviembre de 1964. "Cierran primeros años de las facultades nocturnas de la Pedagógica".

${ }^{50}$ El Tiempo, 3 de mayo de 1966.

${ }^{51}$ El Siglo, 13 de julio de 1967.

${ }^{52}$ El Siglo, 13 de agosto de 1967

${ }^{53}$ El Siglo, 21 de agosto de 1967. 
El estudiantado, por su lado radicaliza su posición, exigiendo la renuncia de la rectora Irene Jara de Solórzano, la cual, después de nueve años de experiencia en la ocupación de su cargo, "no ha querido ceder a las justas peticiones del movimiento estudiantil que compone el Comité Pro defensa de la UPN" ${ }^{24}$. Esta rectora al igual que Radke, diez años antes, recibe el apoyo y la solidaridad del Instituto Pedagógico Nacional ${ }^{55}$. Aunque los estudiantes no logran la renuncia de la rectora, pues a comienzos de 1969 sale de su cargo más por una iniciativa presidencial que cobijó a todas las instituciones públicas del país, sí logran dejar un ambiente en el que la Universidad Pedagógica debe iniciar un proceso de reforma académica y administrativa. Producto de esta coyuntura, uno de los últimos artículos que toca este tema da a conocer:

\begin{abstract}
"Se llega a la conclusión de que estamos fallando en la formación de movimientos pedagógicos contemporáneos. La reforma de Normales actualizó la formación de maestros, pero la reforma que se necesita para formar licenciados, no se ha producido, se siguen viejos moldes académicos, programas quedados en movimientos pedagógicos de los 40 o 50. Necesitamos actualizarnos. No hemos logrado que las facultades Pedagógicas dejen de lado el academicismo y pasen a verdaderos laboratorios. La formación pedagógica requiere de un gran cambio, o nos atropellaran los tiempos sin actualización"56.
\end{abstract}

El estudiantado de 1967 y 1968 tuvo un carácter eminentemente académico. Hacia estos años se comienza a evidenciar una crisis de pedagogía en la Pedagógica. Si bien, la escuela activa, había servido como propuesta para la formación de docentes, ésta comenzaba a ser revaluada por las nuevas generaciones, y las nuevas necesidades y visiones del mundo que se comenzaban a respirar. Después de un agitado debate, el primer semestre de 1968 se inició con las correspondientes sanciones de parte de las directivas hacía los estudiantes que lideraron el movimiento de 1967. Es así como al estudiante Luis Eduardo Lara Gutiérrez, del curso de Español y Literatura,"quien por medio de su actuación afectó la marcha regular de las clases de los cursos nocturnos del segundo semestre de 1967, organizando y participando en manifestaciones ofensivas contra las autoridades de la universidad, colaborando además en campañas de prensa lesivas contra el buen nombre de la institución, el Consejo Académico resuelve imponerle matrícula condicional para el primer semestre de 1968, matrícula que será cancelada a la primera reincidencia de esos actos. Faltas que han sido previstas en el reglamento de la universidad en el Decreto Legislativo 2688 de 1966" ${ }^{\prime 27}$.

Igual sanción se le aplica al estudiante Evelio Zuluaga, de la Facultad de Psicología y Pedagogía, quien participó en actos atentatorios contra la seguridad de los miembros de la universidad ${ }^{58}$; y al estudiante Néstor Alvira, también de la facultad de Psicología y Pedagogía quien fue uno de los elementos más perturbadores de la campaña que afectó el orden universitario ${ }^{59}$. Este último estudiante, de manera anecdótica un año después solicitaría que se le levantara la sanción con motivo de la visita del Papa Paulo VI, pues el gobierno nacional concedió indulto y rebaja de penas a los presos de ese entonces. Las directivas le dan a conocer que no se le ha tratado como delincuente y que la sanción, por demás, es transitoria ${ }^{60}$.

\footnotetext{
${ }^{54}$ Ibid.

${ }^{56}$ El Siglo, 17 de octubre de 1967.

${ }^{57}$ Resolución Número 01 de 1968. Archivo de Rectoría UPN.

${ }^{58}$ Resolución Número 02 de 1968. Archivo de Rectoría UPN.

${ }^{59}$ Resolución Número 03 de 1968. Archivo de Rectoría UPN.

${ }^{60}$ Acta Número 30 de 1968. Consejo Académico. Archivo de Rectoría UPN.

${ }^{55}$ El Siglo, 28 de agosto de 1967. La Asociación de padres de familia del Instituto Pedagógico

Nacional aprobó en una sesión general una moción de respaldo a la gestión de la rectora. 
Con estas sanciones y este hecho anecdótico terminaría una lucha estudiantil que marcaría la historia de la institución, que desde ese año comenzó un agitado proceso de discusión y reestructuración interno en el cual se recogerían algunos puntos solicitados por el estudiantado de los años sesenta.

\section{El estudiantado y la administración de Jaime Sanín Echeverri}

Para finales del primer semestre de 1969, llega a la administración de la universidad el primer rector hombre, persona de altas calidades académicas y políticas, de manera particular en el ámbito de la educación superior. Nos referimos a Jaime Sanín Echeverri. Bajo la administración de este ideólogo del partido conservador, que se extiende hasta 1972, la Pedagógica viviría grandes cambios ${ }^{61}$.

Este rector, definido por los profesores como un humanista y un liberal en su visión del mundo y de la universidad, transformaría, tal vez sin quererlo, a la institución ${ }^{62}$. Se puede decir que la universidad "Germano- Boyacense" vive una importante ruptura y transformación. La universidad tradicional apegada a costumbres religiosas y católicas, acompañada de carnavales, reinados, comparsas y consagraciones religiosas llegaría a su fin por la presencia de nuevos actores, a los cuales Sanín Echeverri les dio cabida. En su administración se pasa de una universidad de predominancia femenina a la presencia masificada de los hombres en las facultades diurnas. Además, se da la entrada a un importante número de profesores críticos de la realidad nacional, como, Néstor Gutiérrez, Fernando Dejanón y Jorge Mora entre otros; y ante todo enfrenta la consolidación del movimiento estudiantil de una manera abierta al diálogo y a la discusión.

La universidad para 1969 aún mantenía un carácter femenino pese a una disposición de la reforma de 1962, la cual obligaba a la institución a transformarse en mixta. Sus directivas encabezadas por Irene Jara de Solórzano, mediante diversas maniobras, habían frenado el proceso. Es Jaime Sanín quien masifica la entrada de los hombres, decisión que traería varias consecuencias como la consolidación del movimiento estudiantil más fuerte que ha tenido la Universidad Pedagógica, además de la vinculación de un número importante de docentes en ejercicio y sindicalizados, que desde un inicio comenzaron a cambiarle la cara a la institución. Leamos al entonces líder estudiantil y posterior líder sindical, Juvenal Nieves:

Yo ingrese a la universidad en el año de 1970, para ese entonces comienza a darse una particularidad muy importante. Por el carácter de Facultad de Educación la gran mayoría de docentes eran maestros en ejercicio del Distrito y en esa medida en cuanto había un movimiento de maestros, ya fuera nacional o distrital, eso comenzó a repercutir en la universidad. Entonces el Consejo Estudiantil comienza asumir dos caracteres: uno político y legal, y otro clandestino; en esa medida los estudiantes comienzan a participar más organizadamente. En esa coyuntura de 1971-73, el movimiento estudiantil de la UPN se

\footnotetext{
${ }^{61}$ Jaime Sanín Echeverri llega a la universidad bajo el precepto presidencial de la Reforma a la Educación Superior 3153 de 1968. Jaime Sanín expresaría en la Pedagógica lo que en el ámbito nacional se conoció como los "Rectores Policías". Sin embargo, es de reconocer que en la mayoría de ocasiones que se presentaron conflictos en la universidad, Sanín buscó la conciliación bajo una visión moralista. Es su sucesor Arturo Camargo quien a finales de 1973 ejercería la función de Rector Policía, y como mano derecha del ejecutivo expulsaría al movimiento estudiantil casi en su totalidad.

${ }_{62}$ En entrevista sostenida con la profesora Mercedes González se establece que la administración de Jaime Sanín tiene un carácter humanístico y liberal. Pese a ser conservador, es una persona abierta a la discusión tanto con profesores como con estudiantes. En su administración se permite la entrada a profesores de pensamiento crítico y de izquierda, que incidiría en el cambio de la cultura institucional. En este período se integran a la institución profesores como Femando Dejanón, Néstor Gutiérrez. Jorge Mora, Gustavo Téllez y Gonzalo Cataño, para solo mencionar algunos casos.
} 
hace fuerte y alcanza a ser más protagonista que el de la Universidad Nacional, pero ante todo por la característica de la presencia de los maestros del distrito como estudiantes ${ }^{63}$.

A la masiva presencia de los hombres y a la relación que comienza a tener la institución con el movimiento magisterial que para ese momento consolidaba un importante proceso de nacionalización y robustecimiento en FECODE. se debe sumar el papel que comenzó a jugar la mujer dentro de nuestra institución y el país. Leamos a la figura femenina más destacada de esta coyuntura, La entonces estudiante Socorro Ramírez:

Cuando yo ingresé a la universidad en 1971, acababa de ser una universidad femenina. Ese movimiento estudiantil de 1971 fue también una ruptura muy importante por cuanto la Pedagógica tradicionalmente había sido una especie de colegio superior para mujeres. Inmediatamente ingresé a la universidad me involucré de lleno con el movimiento estudiantil y con varios colegas de la época ayudamos a forjar la participación de la Pedagógica en los ámbitos del movimiento estudiantil nacional. Luego me vinculé a la corriente socialista y a la vertiente maoísta del partido comunista. Todo desde el ámbito estudiantil. Me vinculé a ese proceso naciente que también para mi fue fundamental, y reivindico hoy como un privilegio haber podido vivir intensamente una época de grandes rupturas en esa institución y en nuestro país.

..Entonces no es tanto por los hombres como por la presencia nueva de la mujer, que abríamos espacio y que ganábamos la vocería de un proceso. Y que en esos encuentros estudiantiles en donde predominantemente casi la totalidad eran hombres los que llevaban la batuta, en buena medida desde la Pedagógica había una ruptura porque las mujeres comenzamos también a disputar un espacio. No un espacio secundario sino de liderazgo que incluso fue muy reconocido por diferentes sectores. ${ }^{64}$

En este período se inicia un importante nexo del movimiento estudiantil de la Pedagógica con el movimiento magisterial encarnado en la ADE y FECODE; pero además se establecen importantes contactos con el movimiento campesino de la ANUC, con el movimiento barrial de los Cerros en Bogotá contra la construcción de la Avenida Circunvalar; y con el movimiento ecologista del momento, que se opuso al entonces presidente Misael Pastrana por la construcción de la Troncal del Caribe que unió a Barranquilla con Cartagena, pues esta vía tapó todas las entradas del mar que llegaban a la ciénaga, base de nutrición de los manglares.

Pero lo que también se recuerda en estos años de lucha estudiantil es la singular cotidianidad frente a la administración de Jaime Sanín. Los estudiantes de la época recuerdan varios hechos paradójicos en la institución, en especial la manera original como este directivo los enfrentó en diversas ocasiones:

De Sanín, yo recuerdo que nos sacaba cartas públicas y las pegaba por toda la universidad, unas dirigidas a los principales dirigentes del movimiento estudiantil, en donde nos hacía

\footnotetext{
${ }^{63}$ Entrevista sostenida con Juvenal Nieves, Bogotá junio de 2000.

${ }^{64}$ Entrevista sostenida con Socorro Ramírez. Bogotá junio de 2000. U. Nal. La vida de esta profesora es sumamente interesante. Ingresa a la Pedagógica en el año de 1971 para salir expulsada en 1973, en las acaloradas luchas del movimiento estudiantil de la época; hacia el año de 1975 se convierte en dirigente de FECODE; en 1978 es candidata a la presidencia de la República por grupos socialistas; en los años ochenta el presidente Belisario Betancur la escoge para acompañar el proceso de paz con las FARC-EP en la Uribe. En el ámbito académico sólo termina su licenciatura en Ciencias Sociales bajo la administración de Augusto Franco hacia 1980. Luego se integra a la Universidad Nacional como Docente e Investigadora del Instituto de Estudios Políticos IEPRI. En esta entrevista manifiesta que entre 1971 y 1973, participó por la Pedagógica en varios encuentros estudiantiles "en Cali. uno en Barranquilla donde detuvieron a buena parte de los asistentes, otro en Medellín con un carácter casi que clandestino, varios en la Universidad del Valle, uno en la Distrital. Cada evento eran de dos o tres días de debate, día y noche hasta la madrugada, discusiones a fondo sobre temas teóricos y políticos, fundamentalmente sobre problemas del país y temas de primera magnitud de la realidad nacional e incluso internacional".
} 
reflexiones sobre cuanto le costábamos al Estado y cuanto le estábamos devolviendo en el tipo de acción y de suspensión de labores y sus implicaciones. Era un rector muy peculiar, yo recuerdo por ejemplo, que había ocasiones que yo estaba dirigiendo una asamblea de esas multitudinarias y él llegaba un poco como para quitarme autoridad o legitimidad a darme un paquete de cigarrillos en medio de la asamblea como para que la gente se sorprendiera. Teñía ese tipo de gestos que eran tácticas de él para contrarrestar un poco el proceso. $^{65}$

Uno de los conflictos internos que desgastó la administración y enfrentó a los estudiantes fue la lucha de éstos últimos en contra del ICOLPE, instituto descentralizado fundado en 1968 para la investigación educativa, que, junto al Plan de Naciones Unidas del PNUD, buscaba la innovación educativa no sólo de la universidad sino del país. Los estudiantes, por su parte, sintieron ajeno al ICOLPE y lo observaron más bien como una burocracia de la educación mientras que al PNUD lo asociaron como la invasión del interés imperialista en el ámbito educativo. Esto originó varias movilizaciones internas entre ellas una que enfrentó directamente el rector Sanín: los estudiantes, una noche se tomaron la sede del ICOLPE; Sanín por su parte buscó una salida intrépida para impedir esta acción y se tiró en cruz a la entrada del edificio desafiando a los estudiantes que pasaran por encima de él. Leamos la manera como lo cuenta el entonces estudiante Rómulo Gallego Badillo:

Mientras nosotros éramos estudiantes el ICOLPE era algo que estaba allá encerrado en el edificio $A$, al cual en el estricto sentido los estudiantes no teníamos acceso, había una élite de investigadores y no había ninguna conexión en realidad con la Universidad Pedagógica. Este sentimiento de aislamiento, de no estar integrado el ICOLPE a la universidad fue generando entre los estudiante de la época una animadversión, hasta que una noche hubo la toma del ICOLPE con todas las leyendas y anécdotas que hay al rededor de la toma. Hubo la toma pero no hubo vandalismo, nosotros no éramos una generación de ese tipo. $Y$ la anécdota es que nosotros nos tomarnos el ICOLPE, el rector de esa época, el Doctor Jaime Sanín Echeverri bajo su responsabilidad, se tendió en el suelo en forma de cruz y todo el mundo pasó por encima y nos tomamos el ICOLPE; luego el ICOLPE salió de la universidad. ${ }^{66}$

Otro hecho, y tal vez el más recordado, es la consagración de la universidad a Santa Teresa de Ávila. La Pedagógica, desde sus orígenes, ha celebrado la semana universitaria, por lo general, del 8 al 15 de octubre. Hasta 1969 y 1970 esta semana estuvo acompañada de reinados, comparsas callejeras, celebraciones eclesiásticas y la consagración de la universidad a la santa patrona, fecha que se festejaba el 15 de octubre. Estas celebraciones fueron interrumpidas por el nuevo tipo de estudiante que comenzó a hacer presencia en la institución en ese entonces. El profesor Rodolfo de Roux, en un artículo, sintetizó este acontecimiento:

Para 1969 durante la rectoría de Jaime Sanín Echeverri, se consagra a Santa Teresa de Ávila como patrona de la UPN y en uno de sus patios se colocó un busto de la santa. Aquellos eran tiempos de agitación universitaria a nivel mundial, continental y nacional. Los estudiantes no perdían la oportunidad para protestar contra ese "acto" retrogrado hasta que llegó el día en que un exaltado dirigente estudiantil quebró de un puño la nariz a la estatua y, de paso se rompió su propia mano. Para evitarle nuevos desaires a la Santa, su busto emigró a los jardines del Instituto Pedagógico Nacional, dependencia de la UPN donde se encuentra actualmente. Lo curioso es que los estudiantes rechazaron a una Santa para adoptar como patrono un nuevo santo de la izquierda cristiana: el cura guerrillero Camilo Torres Restrepo, muerto en combate en 1966 a los 37 años. En la Plazoleta central de la

\footnotetext{
${ }^{65}$ Ibid.

${ }^{66}$ Entrevista sostenida con Rómulo Gallego, febrero del 2000. 
universidad, lugar de todas las concentraciones estudiantiles, se levanta, para arengar discursos, un púlpito en cuya base hay incrustada una placa en memoria de Camilo Torres. ${ }^{67}$

Según Juvenal Nieves, el movimiento estudiantil de esa época de tendencia marxista estaba muy en contra de cualquier creencia religiosa y no iba a permitir que la universidad volviera a ser consagrada a algún rito católico. Y luego, en contraste, ese mismo patio se bautiza como "Patio de la Solidaridad" por parte de los estudiantes, en apoyo a la luchas no sólo del mismo movimiento universitario, sino de la ANUC y del movimiento magisterial entre otros.

\section{El Pliego mínimo y la acción del estudiantado en 1971}

En el año de 1968 la reforma constitucional de Carlos Lleras Restrepo trajo, de manera implícita, el Decreto 3157 que apuntada a la reforma de las instituciones de educación superior de carácter nacional. El Decreto tenía un antecedente personal del año de 1964 cuando, siendo candidato presidencial, los estudiantes de la Universidad Nacional de Bogotá. lo retienen por algunas horas en protesta al supuesto apoyo irrestricto de la institución hacía el líder político liberal. Este antecedente sumado a la agitación estudiantil de finales de la década es cobrado por Lleras.

En el Decreto de reforma 3157 se establece que "son agentes directos del Presidente de la República, de su libre nombramiento y remoción los ministros, los jefes de departamento administrativo y los gerentes de los establecimiento públicos nacionales". Las universidades estatales nacionales, consideradas por ley como establecimientos públicos, quedaron así como meros apéndices del ejecutivo, y perdieron todo tipo de autonomía lograda hasta el momento.

Este decreto, fue nefasto, en términos de orden público, para las universidades oficiales, pues con él vendría la presencia de los "rectores policías", que al depender directamente del ejecutivo abandonaron su función académico-administrativa y pasaron a ser agentes de control del orden público. Se originan así las tomas por parte de los militares a las universidades públicas y el cierre de estas, acompañadas por algunas de las privadas.

Para inicios de la década de 1970 el movimiento estudiantil universitario desarrollaría su última lucha generacional que expresó a la vez un último esfuerzo de lo que quedaba de la FUN. Para esta coyuntura, el estudiantado colombiano ya se había movilizado en contra del Plan Básico de Educación Superior en el cual se hacía un diagnóstico del sistema universitario y hablaba del vacío técnico, el exceso de lo humanístico, y de la baja calidad de los programas. Además, establecía parámetros para la estructuración del sistema educativo, proponiendo mecanismos de regionalización universitaria. Este Plan iba acompañado de la propuesta norteamericana de universidad que se había comenzado a implementar en el país, según los parámetros de Rudolf Atcon, quien estableció la departamentalización, la flexibilidad del currículo, los créditos, y una división tripartida y funcional de universidad: administrativa, profesoral y estudiantil.

Ante estas propuestas y con la reforma de 1968 el estudiantado se movilizó, desde los primeros días de 1969, producto de la reforma constitucional que para algunos fue impuesta. A lo anterior se sumaría el periplo, en mayo de ese año, de Nelsón Rockefeller,

\footnotetext{
${ }^{67}$ Rodolfo de Roux: "Lo sagrado al acecho”, en Revista Colombiana de Educación No. 21. Bogotá UPN-CIUP 1990. p.117.
} 
que con Lleras Restrepo en actitud desafiante, visitaron la Nacional, cuya respuesta fue una fuerte protesta. Por esos mismos días, producto de esta coyuntura, se cierran la Universidad Nacional y la Universidad de Antioquia.

Lleras Restrepo en 1969 haría un recorrido a otras universidades públicas del país incluyendo la Pedagógica ya bajo la dirección de Jaime Sanín Echeverry. Pero la crisis universitaria estalló a comienzo de 1971, cuando de nuevo se dan algunos pasos que buscaban la reconstrucción de la FUN, que el mismo Lleras Restrepo había disuelto cinco años atrás. Luego, en la presidencia de Misael Pastrana, se afrontarían todos estos conflictos acumulados que buscaron ser resueltos por medio de una fuerte movilización nacional de la cual la Pedagógica haría parte.

La crisis se inicia el 7 de febrero de 1971 en la universidad del Valle. Los estudiantes luchan por el gobierno universitario y la autonomía resquebrajada por la reforma constitucional de 1968. El Movimiento pide la renuncia del Rector, pero sobre todo medidas profundas de reorganización; eliminación de la presencia del sector privado (ANDI, FENALCO, etc.) y de la iglesia en el seno del Consejo Superior de la universidad; el rechazo de algunos créditos otorgados por entidades internacionales (en el caso concreto, sobre todo por el BID) en condiciones que se juzgan abusivas; la suspensión de una fundación privada que administraba buena parte de los fondos de la universidad y remuneraba directamente a algunos profesores. Estas reivindicaciones van pronto a ser asumidas por los estudiantes de casi todas las universidades ${ }^{68}$.

Sin embargo, lo que precipita la generalización del movimiento son los sangrientos acontecimientos ocurridos en Cali, el 26 de febrero, cuando en medio de una manifestación estudiantil resultan siete estudiantes muertos y numerosos heridos. La agitación gana entonces espacio en la mayoría de universidades, incluidas las privadas. El 3 de marzo se decreta el toque de queda en Medellín. El 4 de marzo esas manifestaciones prosiguen en Manizales, Bucaramanga, Popayán, Bogotá y Medellín; dos muertos más hay que deplorar, uno en Medellín y otro en Popayán ${ }^{69}$.

Este mismo 4 de marzo la Universidad Pedagógica viviría hechos que aún se encuentran presentes en la memoria de algunos profesores. Los estudiantes de la institución se solidarizan con los acontecimientos anteriormente narrados. En esta institución formadora de docentes en esos momentos se comenzaba a vivir un interesante proceso, bajo la administración de Jaime Sanín, quien había dado mayor participación al sector masculino en las facultades de educación, tanto diurna como nocturna. Dentro del movimiento muchos de los estudiantes eran profesores del distrito en ejercicio, agremiados sindicalmente. Por esas razones, la lucha de los años setenta sería más radical con respecto a las anteriores.

La jornada del 4 de marzo de 1971 ha sido una de las más violentas. El estudiantado, en acto de solidaridad con lo ocurrido a nivel nacional, bloqueó las vías circundantes a la Avenida Chile en las horas de la tarde; la Policía Militar hizo presencia; así se originó un enfrentamiento que se extendió hasta altas horas de la noche. Hubo estudiantes lesionados y detenidos. Se presentó el allanamiento y, por último, la toma por parte de los militares a la institución. En medio de estos actos, los estudiantes lograron la detención de

\footnotetext{
${ }^{68}$ Daniel Pécaut. Crónica de dos décadas de política en Colombia 1968-1988. Bogotá, Siglo XXI. 1989. p. 148.

${ }^{69}$ Para el día 23 de abril se contabilizan 11 universidades cerradas, varias de ellas ocupadas por el ejército. Este es el caso de la Nacional de Bogotá y Medellín, y de la Universidad Industrial de Santander. Se calcula que de 110.000 estudiantes hay 60.000 afectados por cierres.
} 
un empleado de la policía secreta y dos ciudadanos más. Se alcanzó a hablar de perpetrar un secuestro para mantener rehenes con miras a un canje por el personal estudiantil que fue detenido. La universidad fue militarizada por varios días.

El Rector, al día siguiente, rechazó enérgicamente los abusos de los militares y también el comportamiento de una parte del estudiantado, al cual reconviene por su participación en actos subversivos contra la autoridad y los derechos ciudadanos ${ }^{70}$. A la vez hace ver la necesidad de un mayor contacto por parte de las directivas con los estudiantes de las horas nocturnas, con quienes no existen canales de comunicación directos. Por último, agradece la actitud de los profesores, del personal administrativo mayoritariamente femenino, pues permanecieron en sus puestos haciendo cuanto estuviera a su alcance para que el disturbio no tuviera consecuencias mayores. Algunos sufrieron lesiones y otros fueron privados de su libertad.

El Consejo Académico; entre tanto, muestra su preocupación por el resultado académico del semestre, pues se inició un periodo de inestabilidad que se extendería durante todo el año de 1971. Se alteró el orden público y la presencia de los militares alrededor de la institución fue característica. Por su parte, las directivas tomaron la decisión a los días siguientes de exigir la cédula universitaria de identificación para el ingreso a la universidad, decisión que causaría algunos altercados.

A la semana siguiente, el Representante del Consejo Estudiantil, Rafael Barrios, expresa su gratitud al Rector por su comportamiento y por sus gestiones en favor del estudiantado ${ }^{71}$. A la vez da a conocer su preocupación por la situación presupuestal de la universidad y pide que se haga un estudio sobre las relaciones con el ICOLPE, con la participación de los alumnos. Así mismo, los estudiantes toman la decisión de regresar a clases, pero desean que la universidad esté integrada por personas pensantes sobre los problemas nacionales y que se respeten las posiciones ideológicas ${ }^{72}$.

En el ámbito nacional, el 25 de marzo de 1971, los estudiantes presentan un Pliego Mínimo de reestructuración de la universidad, al lado de reivindicaciones relativas a la liberación de alumnos detenidos. El Programa Mínimo exige sobre todo:

La supresión de los Consejos Superiores de las universidades, organismos supremos de decisión, en las que tenían asiento representantes de entidades no universitarias, la participación de estudiantes y profesores en el nombramiento de las directivas en las universidades públicas y privadas; un presupuesto para la educación que sea igual al $15 \%$ del presupuesto nacional, incluyendo los institutos descentralizados, finalmente el mantenimiento de la Universidad Nacional como universidad piloto ${ }^{73}$.

El movimiento para el 29 de marzo gana adeptos dentro de los profesores, quienes exigen una transformación administrativa de las universidades, el regreso de la autonomía que el gobierno anterior había recortado y la supresión del actual Consejo Superior de las Universidades. A fin de mes, el Consejo Nacional de Rectores, se pronuncia igualmente

\footnotetext{
${ }^{70}$ Acta Número 10 del 5 de marzo de 1971. Consejo Académico. Archivo de Rectoría. UPN.

${ }^{71}$ El Consejo Estudiantil es una instancia de peso dentro de la representación estudiantil del periodo. En entrevista sostenida con Juvenal Nieves (junio del 2000), este manifiesta que el Consejo Estudiantil por ellos instaurado reemplaza una tibia representación estudiantil de los cursos que eran muy similar a la de los monitores de los Colegios. De hecho, el Consejo Estudiantil alcanza a participar al menos de los dos últimos reinados y carnavales que tenía la institución en la segunda semana de octubre. El Consejo Estudiantil se politiza por la importante presencia que comienzan a tener los hombres en la institución. sumado a que muchos estudiantes a la vez eran profesores en ejercicio agremiados sindicalmente, elemento que le dió un nuevo carácter a las luchas estudiantiles con el movimiento magisterial. A modo de ejemplo, Juvenal Nieves fue presidente del Consejo Estudiantil durante la coyuntura de 1972 a 1973, para luego ser presidente de la Asociación Distrital de Educadores, ADE, entre 1974 a 1976, cuando todavía no había terminado la carrera de Biología en la Pedagógica.

${ }^{72}$ Acta Número 11 del 10 de marzo de 1971. Consejo Académico. Archivo de Rectoría. UPN.

${ }^{73}$ Daniel Pécaut, Op. Cit. p. 150. 
por una transformación de los consejos superiores, por la autonomía y la reapertura de las universidades.

El entonces ministro de Educación, Luis Carlos Galán Sarmiento, manifiesta en su momento estar abierto al diálogo; al considerar respetables muchos de los planteamientos estudiantiles que apuntaban hacia una verdadera autonomía universitaria. Para el Ministro era necesario eliminar la participación de sectores extrauniversitarios, pues estimaba que la democratización en todos sus niveles es el elemento substancial de la transformación del país. Producto de esta situación da a conocer un proyecto de Reforma Universitaria en mayo de 1971.

Referente a la autonomía, el sistema quedaba bajo el control centralizado de un Consejo Nacional Universitario con Consejos Regionales; los centros oficiales tendrían un carácter de establecimientos públicos adscritos al Ministerio; el rector seguía siendo designado por el Presidente de la República y los profesores eran clasificados como empleados públicos. Sobre la orientación académica de los programas, el proyecto se limita a ordenar que las universidades armonicen su política con la de los planes de desarrollo económico y social, lo cual fue entendido como un sesgo tecnicista. Finalmente en los Consejos superiores habrían dos representantes del estudiantado y dos del profesorado, además del ministro y del gobernador o el alcalde, de un egresado ajeno al claustro y de cuatro decanos; pero las atribuciones de dichos consejos quedaban sin definir ${ }^{74}$.

Este proyecto de Galán, que en algo avanzaba con respeto al gobierno universitario al dar más presencia a miembros de la comunidad universitaria y al eliminar algunos actores externos a la misma; fue blanco de críticas por parte de los profesores de las universidades de Antioquia y Nacional. Pero, fue en realidad el movimiento estudiantil quien derrotó dicha iniciativa, lo que se protocoliza con la renuncia del joven Ministro. La propuesta del estudiantado sobre el Pliego Mínimo seguiría vigente al menos por dos años más cuando se establece en algunas instituciones "el cogobierno" y la presencia de algunos rectores de tendencia marxista.

Por su parte, la Universidad Pedagógica siguió en anormalidad académica por el resto del año de 1971. Producto de los hechos anteriormente narrados, se gesta un movimiento estudiantil de protesta autodenominado "Movimiento 4 de marzo". Para el mes de julio aún se ponía en duda la posibilidad de terminar el semestre. El doctor Sanín observa con beneplácito la solicitud de un importante número de estudiantes, de quienes se sospechaba de haber participado en actos subversivos contra la institución, los cuales buscaban terminar el semestre. Entre los solicitantes se encuentra la líder estudiantil, Socorro Ramírez ${ }^{75}$.

En una posterior reunión se decide darle larga al primer semestre hasta el 4 de septiembre. Para empezar la escolaridad del segundo semestre desde el 6 de septiembre hasta el 23 de diciembre de 1971. Algunos profesores, en esta reunión, ven la necesidad de expulsar a los estudiantes sorprendidos en actos que han alterado la normalidad académica en la institución. El Rector, Jaime Sanín, por su parte, insiste que ante la violencia debe aplicarse la fuerza moral ${ }^{76}$. Después de esta intervención el Consejo Académico pide al Consejo Directivo, para los líderes estudiantiles, la suspensión del semestre; entre ellos se encuentran el futuro líder sindical Juvenal Nieves, la futura

\footnotetext{
${ }^{74}$ Hernando Gómez Buendia. Sindicalismo y politica económica. Bogotá, Cerec, 1986. p. 202.

${ }^{75}$ Acta Número 30 del 13 de julio de 1971. Consejo Académico. Archivo de Rectoría UPN. El Consejo Académico decide en esta reunión dar un carné amarillo a los estudiantes que se comprometan a cumplir con las normas y el reglamento universitario. Los alumnos con matricula condicional tendrán una carné amarillo pero con la palabra "condicional" muy clara y visible.

${ }^{76}$ Acta No. 31 del 16 de julio de 1971. Consejo Académico. Archivo de Rectoría UPN 
académica y líder política Luz del Socorro Ramírez, y un futuro profesor de la institución Rómulo Gallego, quien solicita se le reintegre a la institución ${ }^{77}$.

El año de 1971 fue convulsionado, el día 19 de julio el Rector no ve otro camino que mantener la ayuda de la fuerza pública en el exterior de la universidad para garantizar el ingreso de quienes desean terminar su semestre ${ }^{78}$. Desde entonces el Movimiento Estudiantil 4 de marzo gestaría acciones de inconformismo expresadas, en mítines y pedreas, en las cuales Jaime Sanín Echeverri en la mayoría de ocasiones buscó la solución pacífica. Inclusive servía de garante ante la Fuerza Pública al acompañar a los estudiantes amotinados hasta lo que hoy es la Avenida Caracas y la Carrera Once, con el fin de que no fueran detenidos ${ }^{79}$. Esta situación se extiende hasta el año de 1973, ya bajo la rectoría de Arturo Camargo Castro, quien busca el acercamiento con los líderes del Consejo Estudiantil dirigidos por Juvenal Nieves y Rafael Agudelo. El grupo de estudiantes liderado por ellos desde el 1 de octubre de ese año entraron en una acción de protesta, acompañada por una huelga de hambre que obliga a la cancelación del semestre $^{80}$.

Este período, con continuas pedreas y manifestaciones, tal vez ha sido uno de los más radicales que haya vivido la institución. Durante estos años, la Pedagógica, según los actores de ese momento, cobró mucha más relevancia beligerante que la misma Nacional por su relación directa con otros movimientos sociales ${ }^{81}$. Para el profesor Darío Betancourt, que en esa coyuntura llega como estudiante a la licenciatura de Ciencias Sociales, uno de los elementos que cohesionaba al estudiantado eran los Núcleos de Estudios Sociales, NES, de los cuales existían alrededor de 30 que participaban en "la solución" de varios problemas de la institución (como el restaurante) y de las comunidades pues había mucho trabajo barrial. Para ese entonces, Darío recuerda que la radicalidad estudiantil se expresaba en "la pedrea" liderada por un grupo denominado "La Aérea":

La carrera once era de doble vía. Era la principal. Entonces allí se hacían peajes para cobrar plata para el movimiento. Aquí se hacía una vaina que se llamaba 'La Aérea'. Se subían cincuenta, cien manes, especializados en bolear piedra al techo de estos edificios, y a veces ponían unas poleas por aquí y "las viejas" cargaban la piedra. Y salía un grupo por ahí de 100 o 200 a torear la Policía que formaba en la Porciúncula. La metían a un garaje. Entonces se venía toda la Policía y los manes se entraban, y 'se vaciaba' la descarga de piedra desde arriba. Los sacaban como a unas cinco cuadras. Imagínese desde arriba ${ }^{82}$.

Las demandas del Consejo Estudiantil del cual haría parte el futuro profesor de la institución, Darío Betancourt Echeverry, en el año de 1973, giraron básicamente en torno "al mejoramiento, ampliación y reestructuración de la biblioteca, la dotación y ampliación

\footnotetext{
${ }^{77}$ Ibid. De esta importante generación que aparece como suspendida de la institución también hacen parte: Rafael Barrios Ortega. José Nelson Franco León. Marielena Guzmán Díaz, Carlos Antonio Caballero, Esperanza Pinto Serga, Héctor Quiroga Carrillo, Luis Guzmán Pachón Ovalle, Joel Darío Sánchez Reyes. Dora Pardo Villalba y Hernando Casalins.

${ }^{78}$ Acta No. 32 del 19 de julio de 1971. Consejo Académico. Archivo de Rectoría UPN.

${ }^{79}$ Según Juvenal Nieves, esto hacía parte de la negociación, pues los militares rodeaban completamente a la Pedagógica en busca de desarrollar detenciones. (Entrevista con Juvenal Nieves, junio del 2000).

${ }^{80}$ Acta No. 42 del 9 de noviembre de 1973. Consejo Académico. Archivo de Rectoría, UPN

${ }^{81}$ Según Juvenal, la Pedagógica fue un importante fortín de apoyo de los otros dos movimientos sociales fuertes de la coyuntura, agremiados en la Asociación Nacional de Usuarios campesinos, ANUC, y la Federación Colombiana de Educadores, FECODE, que se encontraba en un proceso de nacionalización sindical. Producto de la radicalidad de ese entonces, a la institución se le apodo la "Piedragógica".

82 Entrevista del Coordinador del Proyecto de Fortalecimiento de Espacios de Participación con Darío Betancourt, marzo de 1999. En esta entrevista Darío manifestó que, cuando llegó a la Pedagógica, "había una organización muy verraca, estaba todo el auge de los años setenta. Entonces uno llegaba aquí a primer semestre y lo que hacían era que lo agarraba un grupo de estudio, eran celulitas de cinco estudiantes y había un trabajo muy ligado con los barrios, con todos los cerros, cuando eso hubo un problema con la avenida de los cerros. Entonces salió una organización estudiantil muy buena. la gente más radical era la de biología y química.”
} 
de los laboratorios; la reestructuración del bienestar universitario y cafetería; la revisión con participación estudiantil de los programas académicos, la reestructuración del ICOLPE y el estudio del presupuesto"83.

Frente a los anteriores hechos, en noviembre de 1973. el Consejo Académico realiza una solicitud al Consejo Directivo: "en vista de que la Universidad Pedagógica Nacional es una institución dedicada a la formación de educadores que propicia la transformación de las estructuras sociales, económicas y culturales del país dentro del orden universitario, que el accionar de una parte del estudiantado no ha permitido el desarrollo de labores académicas, faltando a obligaciones contraídas en la matrícula, acuerda clausurar el segundo semestre de 1973 y suspender la matrícula a los estudiantes que han hecho parte del movimiento del 1 de octubre" ${ }^{84}$.

El Consejo Directivo decide acoger en su totalidad las recomendaciones del Consejo Académico $^{85}$, y suspende la matrícula a 51 estudiantes, entre los cuales sobresalen los ya veteranos dirigentes: Juvenal Nieves Herrera y Luz del Socorro Ramírez, además de Darío Betancourt.

La suspensión y expulsión de casi todo el movimiento estudiantil de la Pedagógica, en palabras de Darío Betancourt, prácticamente mató a un actor importante de la vida universitaria que como movimiento volvería a renacer de manera lánguida ya en la década del ochenta ${ }^{86}$. El movimiento estudiantil de la Pedagógica también nació y murió en el Frente Nacional. Posterior a esta coyuntura, siguió un período crítico bajo el Estatuto de Seguridad del gobierno de Julio Cesar Turbay Ayala (1978-1982), y, luego, un proceso de politización militante de los grupos de trabajo estudiantil en la década de los años ochenta, que incipientemente se antepusieron a las iniciativas de reforma de posteriores administraciones.

\section{El Estatuto de Seguridad de Turbay en 1978}

La crisis del movimiento estudiantil para esos años tiene una respuesta en el ambiente político nacional que se comenzó a vivir bajo la dictadura civil de Julio Cesar Turbay Ayala (1978-1982). El Partido Comunista y la FARC, de ser la matriz de la izquierda colombiana en la década de los años sesenta ${ }^{87}$, para el período de los años setenta y ochenta ya se ha dividido y subdividido en varias propuesta políticas de izquierda con lineamientos marxistas, leninistas, maoístas, troskistas, lo que origina hasta líneas de corte nacionalista. En lo armado los grupos insurgentes también se dividen; nace el Ejército de Liberación Nacional, ELN; el Ejército Popular de Liberación, EPL; y el Movimiento 19 de abril, M- 19, entre otros. Este último grupo surge con una propuesta armada en el escenario urbano en la cual importantes sectores del estudiantado se comprometieron.

Frente a esta situación, el gobierno del presidente Julio Cesar Turbay buscó una salida abiertamente autoritaria. El presidente decretó el Estatuto Nacional de Seguridad, el 6 de

\footnotetext{
${ }^{83}$ Entrevista con Juvenal Nieves. Op. Cit junio de 2000.

${ }^{84}$ Acta No. 42 del 9 de noviembre de 1973. Archivo de Rectoría UPN

${ }^{85}$ Acuerdo No. 113 de 1973. Archivo de Rectoría UPN.

${ }^{86}$ Charlas sostenidas entre Absalón Jiménez con Darío Betancourt en el aula de clase en el año de 1994.

${ }^{87}$ Fabio López de la Roche, Izquierda y cultura políticas. ¿Oposición o alternativa? Bogotá, CINEP, 1994. Esta tesis es manejada por Fabio López de manera particular en el Capitulo 2. Para él todas las organizaciones de izquierda posteriores a la década de los años sesenta tienen su génesis o fueron permeadas por el Partido Comunista y su tesis sobre la combinación de las formas de lucha. En uno de los apartes del texto da a conocer que comprender la cultura política del Partido Comunista en Colombia es comprender en buena medida la cultura política de la izquierda en el país: "En primer lugar, por ser ese partido la fuerza política predominante al interior de la izquierda colombiana, desde su creación en 1930 hasta la revolución cubana de 1959, cuando nuevos movimientos y partidos políticos entran a disputarle su posición directiva y monopólica dentro del campo revolucionario". p. 100.
} 
septiembre de 1978, en desarrollo del artículo 121 de Estado de Sitio de la Constitución Nacional, el cual tenía como objetivo fundamental quitarle la base social a los grupos insurgentes, es decir, "quitarle el agua al pez". El estatuto afectó más a los colaboradores de la guerrilla a los combatientes. Sus disposiciones pueden resumirse en tres grupos: "1) Aumento de las penas previstas para los delitos de secuestro, extorsión, incendio voluntario, ataque armado; puede decirse que prácticamente se doblan. 2) Extensión imprecisa de la noción de subversión que permite castigar con un año de prisión a los que distribuyan propaganda subversiva, exhiban en lugares públicos textos o dibujos ultrajantes o subversivos, que inciten a los ciudadanos a la revuelta o a desobedecer a las autoridades. 3) Atribución a las autoridades subalternas, militares y policiales de la capacidad de fijar penas por estos delitos" ${ }^{\prime 8}$. Además, se les atribuye funciones de Policía Judicial a estas autoridades: la recolección de pruebas y la acusación del sospechoso, el cual perdía todo tipo de garantías procesales.

En virtud de este artículo del Decreto, el Ejército y la Policía procedieron a una primera oleada de arrestos, para desmantelar redes terroristas urbanas. Esta ola afectó sobre todo a estudiantes de la Universidad Nacional, y a miembros del M-19 (recordemos que al terminar el período de Turbay casi que toda la cúpula de este grupo se encontraba en prisión). También fueron puestos presos simpatizantes y miembros del ELN y el EPL refugiados en la ciudad.

Esta situación originó la desmovilización de las organizaciones sociales, en general, pero sobre todo el accionar del movimiento estudiantil, particularmente de las universidades públicas, vistas como focos de colaboradores y guerrilleros en potencia. No en vano en este período la protesta estudiantil en el caso de la Universidad Pedagógica fue satanizada. Los estudiantes después del paro cívico de septiembre de 1977 trataron de acercarse a las reivindicaciones populares. Es así como para el día 10 de mayo de 1978 los estudiantes de la institución participaron en una jornada contra el alza del transporte público, apedreando a una buseta afiliada a la empresa Republicana de Transportes. Se desarrolló un enfrentamiento con la policía, hubo "piedra", contusos y detenidos. Ese día se presentó en el resto de la capital un saldo de cuatro vehículos incendiados $^{89}$.

Posteriormente, en el segundo semestre de 1978 los estudiantes se enfrentaron a los dictámenes de una "rectoría encargada" en manos del profesor Augusto Romero Díaz, quien con intenciones de ratificarse en el cargo, calumnió una protesta estudiantil ocurrida el día 20 de octubre de 1978, cuando manifestó a los medios de comunicación que las protestas que se daban por esos días en la Pedagógica respondían a una lucha de los estudiantes contra el Estatuto de Seguridad del presidente Julio Cesar Turbay ${ }^{90}$.

Dicha acusación, que además de falsa era muy grave en momentos difíciles de la política nacional, trajo graves consecuencias dentro de la institución. Esta administración, que duró relativamente corto tiempo, fue enfrentada con gallardía por parte del movimiento estudiantil. El 17 de noviembre los estudiantes decretaron un paro de 24 horas para dilucidar las verdaderas razones de su inconformismo. Además de denunciar la ineptitud, desgreño e incapacidad administrativa de las directivas de la institución en cabeza del rector encargado, los estudiantes reclamaron un real bienestar universitario,

\footnotetext{
${ }^{88}$ Daniel Pécaut, Op. Cit. p. 320.

${ }^{89}$ El Espectador, 11 de mayo de 1978. "Desordenes en Bogotá."

${ }^{90}$ El Tiempo, 21 de octubre de 1978. "Desordenes en la Pedagógica." 
dotación adecuada del restaurante, construcción de aulas inconclusas, campos deportivos, y un ajuste de la institución a las verdaderas necesidades del país ${ }^{91}$.

A las demandas del Consejo Superior Estudiantil, que se conforma para ese entonces, se sumaría la Asociación de Profesores de la UPN, quien en un comunicado manifiesta que la real causa del inconformismo es la incapacidad del rector para buscar vías que solucionen la crisis financiera por la que atravesaba en ese entonces la institución. Para la Asociación el rector encargado entendía la autonomía como autofinanciamiento, privatización y alza de matriculas. Otras de las razones del inconformismo estudiantil es el carácter represivo de la administración, quien además de contratar una compañía de seguridad privada, recurre a absurdas medidas como el cierre temporal del restaurante, el desmantelamiento del comité de cooperación estudiantil y el anuncio de sanciones para supuestos chivos expiatorios con el fin de dejar precedentes. La Asociación de Profesores y el Consejo Superior Estudiantil solicitan ante estos múltiples problemas, la sustitución de las directivas universitarias, por una que disponga del apoyo y la colaboración de los estamentos universitarios ${ }^{92}$.

La presión del estudiantado junto a la ayuda de los profesores en 1978, lograría, una importante victoria dentro la institución. El rector encargado, Augusto Romero Díaz, renunció no sin antes manifestar que "su decisión se originaba por la presión de la izquierda universitaria y el proselitismo político del magisterio"93. Pero las secuelas que dejó este rector dentro de la institución no fueron las mejores: en una protesta, desarrollada el día 30 de noviembre de 1978, fueron detenidos cuatro estudiantes en 4 inmediaciones de la calle 72: Guillermo León Osorio, Javier Hernández, Antonio Naranjo y William Neira Torres, acusados de haber quemado un campero Toyota de placas oficiales. Los estudiantes tuvieron que afrontar a la semana siguiente un juicio en un Consejo de Guerra, en momentos en que se daba el cambio de la administración ${ }^{94}$.

Este grupo de estudiantes que fueron sentenciados a doce meses de prisión, en el juicio, por medio de sus abogados denunciaron violación a sus derechos, pues desde el momento de su captura y por espacio de 72 horas los militares los mantuvieron vendados, no los dejaron dormir, tampoco les permitieron sentarse y fueron sometidos a un continuo interrogatorio en los Patios de la Brigada del Instituto Militar. En el juicio se logró establecer, además, que su captura se originó en un trabajo de inteligencia del Ejército, el cual logró infiltrar a un agente del B-2: dragoniante de la Policía Militar Edgar Muñoz, quien durante dos meses estuvo asistiendo a clases en la Universidad Pedagógica. Este sujeto fue a la vez el único testigo que reconoció a los sindicados ${ }^{95}$.

Sin duda, que lo ocurrido en la Pedagógica fue una pequeña muestra de las consecuencias que trajo el Estatuto de Seguridad de Turbay dentro de las universidades públicas. La principal secuela de Estatuto fue la desarticulación de las organizaciones estudiantiles. Para la década de los años ochenta se iniciaría una serie de procesos organizativos y de protesta. Pero con los respectivos temores por parte de los dirigentes, quienes no lograron una articulación gremial de importancia en el ámbito nacional.

\section{El estudiantado de la década de los ochenta}

\footnotetext{
${ }^{91}$ El Tiempo. 18 de noviembre de 1978. "Fue levantado el paro en la u. Pedagógica".

${ }^{92}$ El Espectador, 18 de noviembre de 1978. "Profesores y estudiantes hablan sobre crisis en la U. Pedagógica"

${ }^{93}$ El Tiempo, 1 de diciembre de 1928. "Renuncia Rector de la Pedagógica y censura agitación política."

${ }^{94}$ El Tiempo, 5 de noviembre de 1978. "Consejo de Guerra a 4 universitarios".

${ }^{95}$ El Tiempo, 9 de noviembre de 1978. "Condenados estudiantes de la Universidad Pedagógica" 
Después de los acalorados enfrentamientos de la primera mitad de los setenta y las secuelas del Estatuto de Seguridad de Julio Cesar Turbay, vendría un período de relativa calma a nivel estudiantil. Líderes del movimiento de los años setenta como Juvenal Nieves y Socorro Ramírez volverían a la universidad, pero ya no a participar de las organizaciones y luchas del estudiantado sino simplemente a terminar sus carreras truncadas de manera arbitraria e injusta, en el año de 1973, bajo la administración de Arturo Camargo, cuando es expulsado el movimiento estudiantil en su totalidad ${ }^{96}$.

El movimiento estudiantil en los primeros años de la década de los ochenta, irrumpe de manera desorganizada. El país vive de nuevo una crisis universitaria en la que son cerradas, en el caso de Bogotá, las universidades Distrital y Nacional. Sin embargo, el estudiantado de estos años no logra articularse en el ámbito nacional, ni logra establecer plataformas conjuntas como sí ocurrió en 1971. El estudiantado, como organización social en la década de los años ochenta, tiene una incipiente participación en la vida nacional; para algunos prácticamente se pierde del escenario político y social de los colombianos, con respecto al importante papel que jugó como actor colectivo durante el Frente Nacional.

Como lo observamos, tal vez el movimiento estudiantil de la década de los años ochenta fue neutralizado desde afuera de la institución por la coyuntura política que se vivió desde el año de 1978, por los menos, hasta 1982, cuando bajo la presidencia de Belisario Betancur el país entró en un proceso de diálogo y reconciliación nacional. Se inicia el proceso con las FARC, se firman indultos y amnistías y finalmente se llega al Acuerdo de la Uribe en el año de 1984. Bajo este ambiente de la presidencia Betancur se da un breve resurgir del movimiento estudiantil.

En el caso de la Pedagógica, el estudiantado reacciona en la administración de Augusto Franco, quien llegó a implementar la reforma a la educación superior conocida como el Decreto-Ley 080 de $1980^{97}$. Bajo esta administración se debe reconocer que al inicio el estudiantado vivió una pequeña "luna de miel" con Franco Arbelaez, que perduró hasta el segundo semestre de 1979. En este año el estudiantado junto a la administración se comprometen en un "jornada de rescate de la universidad", en la que se desarrolla un cambio en su planta física, cuya primera etapa consistió en un lavado de rostro de la universidad con agua y jabón, acompañada de una gran dosis de alegría. Se pintaron paredes y pupitres y se recuperó el costado occidental de la universidad, bautizado por los mismos estudiantes como el "Mar muerto"y en el que se hallaba una construcción abandonada junto al edificio $\mathrm{P}$, para ese entonces en ruinas. Con la pintura y el restablecimiento general hecho por los mismos estudiantes se buscó crear conciencia de que la universidad era para su uso y que debía permanecer en buen estado, además de lo anterior se desarrolló una jornada de arborización en compañía de la $\mathrm{CAR}^{98}$.

\footnotetext{
${ }^{96}$ Juvenal Nieves vuelve a la universidad en el año de 1977 a terminar su licenciatura en Biología, después de haber sido presidente de la Asociación Distrital de Educadores, ADE, y de haber enfrentado de manera exitosa la propuesta del Estatuto Docente de Luis Carlos Galán. Socorro Ramírez regresa en la década de los años ochenta, bajo la administración de Augusto Franco, para terminar en la Licenciatura de Ciencias Sociales en momentos en que ya era reconocida como una figura nacional y líder sindical de la FECODE. Rómulo Gallego terminó su licenciatura en Química, de una manera más o menos calmada con relación a la de sus compañeros generacionales, después de haber participado de los acontecimientos de marzo de 1971, y se incorporó luego a la universidad primero como monitor del laboratorio de Química y después como profesor catedrático. Uno de los que no vuelve en calidad de estudiante es Darío Betancourt, quien pasa por otras universidades: la Nacional y la Libre donde finalmente termina la licenciatura. En el año de 1988 regresa a la Universidad Pedagógica pero en calidad de profesor catedrático.

${ }^{97}$ EL Tiempo, 24 de enero de 1979. "Franco Arbelaez rector de la Universidad Pedagógica." Según la entrevista colectiva sostenida con los profesores Mercedes González, Mercedes Ayala y Germán Bautista, el rector Augusto Franco (1979-1984) en la primera etapa de su administración desarrolla la reforma administrativa de manera autónoma e independiente. En el momento en que inicia la reforma académica convocó a los profesores a la discusión. En esta administración se establecen los estatutos administrativo, docente y estudiantil que perduran hasta prácticamente el año 2001.

${ }^{98}$ El Tiempo, 18 de junio de 1979. "Al rescate de la universidad." 
Sin embargo, la reforma 080 de 1980 fue vista como una imposición venida desde afuera, sin la posibilidad de ningún consenso ni rasgo de participación democrática por parte no sólo de los profesores, sino además de los estudiantes. Al Doctor Augusto Franco se le identificó como un tecnócrata de la educación, el cual mediante su visión administrativa de universidad no permitió espacios reales de discusión y participación en el proceso de la reforma universitaria. En esta coyuntura, profesores y estudiantes se pronunciaron frente a la manera como se desarrolló la reforma.

Para el profesor Gustavo Tellez, "la reforma implantó una estructura vertical, jerárquica de poder, que eliminó gran parte de la autonomía que tenía la universidad para dictar su propias normas. El proceso de reforma metió a la universidad en la camisa de fuerza de la legislación, concretamente en el Decreto 080 de 1980"99. Por su parte, los dirigentes estudiantiles también denunciaron el verticalismo desarrollado en el proceso de reforma; la estudiante Patricia Pardo así lo da a conocer:

Lo que nosotros sabemos de la aplicación de la reforma es muy poco y fundamentalmente, a través de algunas medidas que se han venido implementando. El acuerdo aprobado por las directivas de la universidad, se dió cuando nosotros estábamos en vacaciones. Este acuerdo plantea además una serie de medidas disciplinarias para el estudiantado, tales como la asistencia obligatoria a clases, como una forma de elevar el nivel académico. Por otro lado se plantean otra serie de normas mediante las cuales se impide al estudiantado que tenga una expresión política y no pueda plantearse una serie de reivindicaciones. Se señala en la norma, por ejemplo, que el estudiantado que participe en huelgas será objeto de sanciones que van desde el llamado de atención hasta la expulsión de la universidad. ${ }^{100}$

En esta coyuntura se inicia un proceso en el que se demanda mejorar los canales de comunicación entre estudiantes, profesores y directivas universitarias. Para las instancias inferiores las directivas trabajaron la reforma aislándose del aporte y las opiniones del conglomerado universitario. Si bien la administración de Augusto Franco ha sido una de las más sólidas y fuertes que ha tenido la institución, el proceso de reforma que finalmente sacó adelante de manera vertical originó una serie de conflictos fuertes con los estudiantes, quienes en el fondo no comprendieron el proceso.

Algunos estudiantes de la época, como el actual profesor Alfonso Torres, aún recuerdan que para el atardecer del 4 de junio de 1980, cerca de 400 estudiantes se tomaron la rectoría y las instalaciones del centro docente, bloqueando las puertas de acceso e impidiendo la salida del rector Augusto Franco ${ }^{101}$. Para los estudiantes la reforma además de vertical y poco participativa traía implícita un incremento de las matriculas, pues se comenzaba a solicitar semestralmente la declaración de renta. Otro punto de la huelga fue la reincorporación de cinco estudiantes expulsados en el año anterior $^{102}$.

Para el rector la verdadera causa del movimiento fue la molestia que causó el nuevo estatuto estudiantil al establecer la obligatoriedad de la asistencia a clase, además del requisito en cada materia de un mínimo de cuatro notas, y no una sola como se hacía anteriormente. Otra causa del inconformismo fue la política de convertir a la Pedagógica

\footnotetext{
${ }^{99}$ El Espectador, 25 de mayo de 1980. “¿Participación de la UPN, un sueño?”

${ }^{100}$ Ibid.

101 Charlas sostenidas entre Absalón Jiménez y Alfonso Torres, profesor del Departamento de Sociales de la UPN, noviembre de 2000.

${ }^{102}$ El Tiempo, 5 de junio de 1980. “La U. Pedagógica ocupada por 400 estudiantes; retenido el rector Franco A.” 
en un centro de experimentación educativa y didáctica ${ }^{103}$. En el relato del entonces rector se recogen los siguientes apartes de "la toma" del 4 de junio:

Todo comenzó cuando la rectoría citó a elección de representantes estudiantiles al Consejo superior y al Consejo de cada facultad, de acuerdo con la nueva reforma universitaria. Las elecciones estaban previstas para el miércoles, día de la toma. El día anterior se registraron algunas asambleas estudiantiles de grupos.

El día miércoles hable en la tarde con un amplio grupo de estudiantes. Mientras tanto otros preparaban el cierre y me enteré de la toma cuando fui a salir a las 6 de la tarde.

Acudí a la persuasión, al diálogo, pero fracasé. Los estudiantes comenzaron a lanzar gritos contra la reforma universitaria, el reglamento estudiantil y el reintegro de tres estudiantes expulsados el año pasado. A esa misma hora fui invitado a una asamblea de estudiantes. Yo sugerí que una delegación me visitara en el despacho. La fuerza pública en ese momento acordonó el sector.

A las 9 de la noche, una comisión de estudiantes me visitó en rectoría, con la exigencia que en diez minutos respondiera un cuestionario de diez puntos: exigir al Ministro de Defensa el retiro de la fuerza pública, libertad para todos los estudiantes detenidos, que no allanaran la institución, que no se cerraran las clases y que no se aplicaran represalias. Estos eran los puntos iniciales de la negociación. Yo como rector reiteré el pedido de abrir las puertas, con la seguridad de que la fuerza pública no intervendría. Pero no accedieron. La noche transcurrió en diálogos y asambleas estudiantiles en la cafetería.

Hasta que a las 4.30 de la mañana se agotó la vía del diálogo. La fuerza pública fue informada de cuanto ocurría adentro. Los estudiantes a esa hora formaron barricadas en las puertas con los pupitres, y escritorios, hicieron hogueras. Se inició la toma de la Policía a las 5:45 de la mañana, se desató una guerra de piedra, botella y vidrios "Revista Colombiana de Educación No. 21. Bogotá UPN- CIUP 1990".

Lo más grave era que gritaban que había que tomar al rector de rehén. Unos cien muchachos penetraron en la rectoría causando destrozos. Querían tomarme de "mampara" para que nada pasara. La desesperación cundió cuando la policía penetró. Los estudiantes rompieron todo y se metieron donde pudieron. Mi escritorio quedó hecho trizas, fue una debacle en cinco minutos. Creo que la acción de la policía fue inteligente y exitosa, fuera del bolillo que a todos les tocó no hubo actos de sangre. ${ }^{104}$

Después de estos graves hechos de protesta frente a la administración de Augusto Franco y la reforma 080 de 1980, la universidad terminó ese semestre con cierta irregularidad académica que originó el adelantó de vacaciones, sumado a un saldo de 240 estudiantes sancionados con matricula condicional, quienes fueron involucrados en la toma. Esa sanción corrió para el segundo semestre de ese año ${ }^{105}$.

Después de esta coyuntura, los estudiantes de la Universidad Pedagógica responden a la crisis en la educación superior que se comienza a evidenciar hacia 1981, año en que "la crisis fiscal" hacía prever tiempos difíciles para el gasto social. Frente al déficit de la universidad las posibilidades de incrementar aportes del presupuesto nacional para educación superior se agotan. Se comienza a hablar desde ese entonces de fuentes alternativas de financiación. Desde esos años se inicia el desmonte de la universidad publica, mediante el establecimiento del "Decreto 728 de 1982, según el cual a partir de la vigencia fiscal de 1983 el presupuesto nacional no financiaría más del 90\% de

\footnotetext{
${ }^{103}$ El Tiempo, 6 de junio de 1980 "Desalojo y cierre de la Universidad Pedagógica".

${ }^{104}$ Ibid.

${ }^{105}$ El Tiempo, 16 de junio de 1980. "Hoy reabren la U. Pedagógica".

Digitalizado por RED ACADEMICA
} 
entidades oficiales, así disminuye progresivamente hasta llegar al 70\% en' 1990”106. Dicha legislación se queda en el papel, pues para 1984 todavía los aportes para las universidades públicas eran del $94 \%$, y para finales de la década eran del $80 \%$. Sin embargo, como todos sabemos los recortes fiscales han seguido originando crisis en el sector desde entonces.

La defensa de la universidad pública se convierte en la principal bandera de lucha de los estudiantes que se lograron organizar en esos años. La Pedagógica, haciendo parte de la Unión Nacional de Estudiantes de Colombia, UNEC ${ }^{107}$, desde el segundo semestre de 1982 se une a una movilización y protesta nacional que origina una crisis universitaria, la que a su vez responde a la intención del Estado de hacer un recorte presupuestal. En esta movilización sumada a la crisis universitaria nacional salen expulsados ocho estudiantes de la Universidad Pedagógica, 60 de la Nacional y 170 de la Libre; de nuevo se dan una serie de cierres en las universidades públicas entre ellas la Nacional.

La Pedagógica, por su parte, inicia un proceso de presión interna frente a la administración en el primer semestre de 1983 y logra establecer una mesa de negociación con las directivas de la institución, y con participación directa del ministro de Educación Jaime Arias Ramírez y su representante en el Consejo Directivo de la Universidad: Gabriel Betancur Mejía. Los puntos centrales de la mesa de negociación fueron: "el alza de las matrículas, y el recorte del presupuesto que para ese año quedó en \$ 102.000.000.00 saliendo afectada la investigación, el bienestar universitario y la biblioteca"108. Por esta razón los estudiantes se declararon en "asamblea permanente" y desarrollaron una serie de marchas masivas con participación, según los medios de comunicación, de 4.600 estudiantes, unas hacia el Palacio de Nariño y otras hacia el ICFES ${ }^{109}$.

La situación llegó al punto que la universidad enfrentó dos semanas de parálisis en el mes de febrero de 1983. Para esta coyuntura ya el MOIR logra darle un sentido político a la lucha estudiantil. Inclusive uno de sus dirigentes, Carlos Alberto Guarín de la Comisión Estudiantil, logra un diálogo directo con el Ministro de Educación, con quien coordina una mesa de trabajo para discutir los puntos de demanda del estudiantado. Lo importante de estas jornadas de 1983 para el representante del MOIR fue que:

Ante todo se demostró que el movimiento estudiantil de la Pedagógica ha alcanzado una madurez evidente al conducir el movimiento con orden e inteligencia, llegándose a acuerdos básicos en el gobierno y las directivas ${ }^{110}$.

Para el mes de marzo de 1983, la gran mayoría de estudiantes expulsados buscan ser reintegrados mediante una amnistía emanada del Ministerio de Educación. Sin embargo, el entonces, ministro, Jaime Arias Ramírez, da a conocer que "la amnistía no cobijará a elementos subversivos dentro de la universidad". Al mismo tiempo, los estudiantes de la UNEC envían una carta a la Comisión de Paz que íntegra el presidente Belisario Betancur para dialogar con los alzados en armas con el fin de llegar a una solución ${ }^{111}$.

\footnotetext{
${ }^{106}$ Ricardo Lucio y Mariana Serrano, La educación superior. Tendencias y políticas estatales, Bogotá, IEPRI, U. Nal., 1990. p. 194.

${ }^{107}$ Llama la atención observar que históricamente las organizaciones estudiantiles adoptan nombres y consignas muy similares de una generación a otra. Recordemos que la UNEC también existió en la década de los años cincuenta, cuando las organizaciones estudiantiles respondían a los lineamientos del bipartidismo en el país.

${ }^{108}$ Semanario Voz, 17 de marzo de 1983. p. 7. El entonces representante al Consejo Académico por los estudiantes. Juan Carlos Orozco, quien hoy es Vicerrector Académico de la institución manifiesta que para esa época todavía había una buena capacidad de convocatoria de los líderes estudiantiles. Se organizaban grandes asambleas y marchas sin la necesidad de bloquear ni entorpecer el desarrollo académico o administrativo de la institución. (Entrevista sostenida julio del 2000).

${ }^{109}$ El Tiempo, 10 de marzo de 1983. "Marcha de estudiantes a Palacio."

${ }^{110}$ El Espectador. 17 de febrero de 1983.

${ }^{111}$ Semanario Voz, 17 de marzo de 1983. 
En términos generales, la mesa de negociación que logra establecer el MOIR junto a la administración de la Pedagógica y el Ministerio de Educación al parecer no tuvo ningún resultado positivo para el estudiantado. Para el mes de marzo, los estudiantes denunciaron la actitud reaccionaria de Franco Arbelaez, quien no cede en sus peticiones $^{112}$. El fracaso de esta mesa también se constata en la declaración continua de asambleas permanentes con el fin de estudiar la difícil situación presupuestal de la universidad pública.

En este sentido, para el mes de julio de 1983. los estudiantes seguían denunciando, mediante un tropel callejero, el recorte del presupuesto de la universidad en 102 millones de pesos, la exagerada alza en los postgrados que llegó a un 300\% y el alza en el servicio de restaurante en un 25\%. Denunciaron, igualmente. la expulsión de estudiantes el año anterior, en el que se destaca la estudiante Patricia Pardo, y la imposición de reglamentos internos ${ }^{113}$.

Se debe reconocer que en este último esfuerzo de los estudiantes frente a la administración Franco, el rector cedió en el punto de rebajar el precio del restaurante, cuyos precios volvieron a ser los anteriores. Pero frente a la petición de posibles reintegros, decisión que también pasaba por sus manos, nunca cedió. El propio Ministro de Educación manifestó para esos días que el gobierno había concedido una "amnistía política" y no académica, además dicha decisión seguía siendo autónoma del Consejo Superior de la universidad ${ }^{114}$.

En la primera mitad de la década del ochenta los grupos de trabajo estudiantil se encuentran politizados hacia la izquierda, y buscan las orientaciones de grupos que, como la Juventud Comunista JUCO y el MOIR, ganan presencia dentro de la institución. Se debe reconocer que estos grupos daban cierto nivel a las discusiones estudiantiles, así se dejaba de lado el pequeño mundo de la calle 72 para discutir aspectos de la realidad nacional e internacional ${ }^{115}$. Ejemplo de lo anterior fueron los puntos discutidos por la UNEC, de la cual su presidente era el estudiante de la Pedagógica Henry Botero: su organización, en un encuentro estudiantil a finales de marzo de 1983, discute la solidaridad con Centroamérica, la situación de la universidad y la organización estudiantil. En este encuentro participaron 18 universidades públicas y ocho privadas con 252 delegados $^{116}$.

La dinámica de la izquierda, en el ámbito nacional, se reflejaba en las discusiones internas y las luchas dentro del mismo estudiantado. El triunfo de Henry Botero, presidente de la UNEC, como representante de los estudiantes al Consejo Superior Universitario (1984-1986), fue visto como un triunfo de la JUCO y un retroceso de la extrema izquierda maoísta ${ }^{117}$. Una de las primeras denuncias hechas por el nuevo representante

\footnotetext{
112 Semanario Voz, 24 de marzo de 1983. P6.

${ }^{113}$ El Tiempo, 4 de julio de 1983.

${ }^{114}$ El Tiempo, 16 de julio de 1983.

115 Posteriormente a estos grupos, ya a finales de la década del ochenta, se sumaria la presencia de otros dos actores políticos con presencia nacional, que en el ámbito juvenil en la Pedagógica tuvieron un importante impacto. Tal como lo fue la presencia de la juventud que militaba en la Unión Patriótica, la cual nace en 1985 después de los Acuerdos de la Uribe, y a finales de la década, el M-19, que logró tener una célula de simpatizantes autodenominados: "Célula Vera Grave". Estos grupos alcanzaron a hacer empalme con la generación de comienzos del noventa. Esta última Célula jugó un papel importante en el acercamiento de la universidad con el M-19 en el momento de su desmovilización. El M-19 junto al EPL aceptarían la presencia de la Pedagógica corno institución en el proceso de reinserción, mediante una propuesta educativa para la paz y la democracia.

116 Semanario Voz. 28 de marzo de 1983.

117 Semanario Voz, 29 de marzo de 1984. La JUCO en estas elecciones asegura haber ganado más del $60 \%$ de las instancias de representación estudiantil de las facultades y los departamentos.
} 
fue acusar a Franco de facilitar la presencia de la Policía en las asambleas estudiantiles y la expulsión sistemática de estudiantes que pertenecían a la JUCO. Se debe anotar que las dos organizaciones políticas del momento valoraban los espacios de representación estudiantil, y buscaban mantener presencia en esas instancias, avalando cuando no, en ocasiones a sectores independientes:

En este periodo - manifiesta el entonces representante Juan Carlos Orozco- aunque había un movimiento estudiantil crítico no contaba con la fuerza organizativa y de movilización de los años setenta. Se forma un movimiento estudiantil, del que yo hice parte, que comenzó a canalizar todos sus esfuerzos en la realización de actividades de tipo académico, en periódicos murales, la constitución de grupos de estudio. En ese entonces no se contó con capacidad de concertación por parte de la administración Franco. Es en esa coyuntura que llegó como representante estudiantil al Consejo Académico como sector independiente. En ese entonces lo elegían los representantes de facultad. Llegó corno independiente aunque con el aval de las dos fuerzas del momento, la JUCO y el MOIR ${ }^{118}$.

Augusto Franco para comienzos de 1985 entrega la administración de la universidad, dejando una huella profunda a nivel administrativo y estatutario. Los estudiantes, por su parte, suavizaron sus relaciones con la siguiente administración, la de Francisco Cajiao. El nuevo rector actuó de una manera más abierta a la discusión y a la participación. En su administración se recuerda que fue una de las personas que facilitó el puente de comunicación entre la Pedagógica y el Movimiento Pedagógico Nacional, junto a la expresión sindical del magisterio: FECODE.

Sin embargo, en este período revivió la presión hacia las universidades públicas y los movimientos sociales ante todo magisterial y estudiantil. Hacia el año de 1987 aparece una publicación gestada por la extrema derecha en Colombia, la cual tuvo una difusión nacional. Todo parece indicar que en esta publicación participaron sectores académicos fusionados con la derecha del país, así se consolidó un grupo que se autodenominó IDEAS (Integración para el Desarrollo y la Acción Social). Se recuerda que en uno de los números de ese año, titulado "Soberanía Violada: la URSS en Colombia", se daba a conocer como existía un plan desde la Unión Soviética para penetrar políticamente nuestro país y crear desestabilización dentro del Estado. En esta tarea de infiltración, para el grupo IDEAS, jugarían un papel importante los maestros y estudiantes de tendencia izquierdista. En varios de los apartes de este documento sale comprometido el nombre de la universidad y el de varios de sus profesores:

Los soviéticos se han preocupado siempre por los maestros, los cuales han organizado un centro de investigaciones Educativas del denominado "Movimiento Pedagógico" que reúne a estudiantes y multiplicadores marxistas entre los maestros, y la publicación de una revista de divulgación con clara tendencia marxista. La presencia de profesores marxistas en colegios de cualquier nivel, en el sector privado, es detectada a través de los libros que recomiendan a autores y temas procomunistas. En el sector universitario estatal es notoria su presencia, destacándose por su activismo las de Bogotá entre ellas: La universidad Pedagógica Nacional, la Distrital, y en el sector privado la universidad Cooperativa y la Inca $^{119}$.

En otros apartes de este mismo documento comprometen el nombre de uno de los profesores más prominentes de la institución:

\footnotetext{
${ }^{118}$ Entrevista sostenida con el Vicerrector Académico de la UPN, Juan Carlos Orozco, junio del año 2000.

119 Revista IDEAS, "Soberanía violada: la URSS en Colombia", Bogotá 1987. P.15 Centro de Documentación del Departamento de Sociales. UPN. (Esta revista dice tener presencia en otras ciudades además de Bogotá como: Medellín, Cali, Barranquilla, Pereira, Pasto, Bucaramanga, Manizales. Montería Armenia, Cartagena, Popayán, Sincelejo, Tunja y Cúcuta.) 
....autores de formación marxista, se han dedicado en los últimos años a escribir textos de estudio para primaria y secundaria con el fin de comenzar en los niños la tergiversación de la historia, dándoles una visión acomodaticia para que se inicien en la lucha de clases, odien los partidos tradicionales, las instituciones democráticas y se inclinen por la solución marxista. Son conocidas las editoriales de "El Cid" y "Estudio" por sus historias de Colombia y América, cuyos autores son el jesuita y ex director del CINEP Rodolfo de Roux, hoy profesor de la Universidad Pedagógica ${ }^{120}$.

Más adelante además de acusar al profesor de la Universidad Pedagógica Rodolfo De Roux, también acusa a otro profesor de nuestra institución, Rafael Ávila quien "con su línea liberacionista de la religión también favorece los planteamientos de la educación marxista pro soviética ${ }^{121}$.

Producto de estas presiones, la Universidad Pedagógica en el año de 1988, pierde a uno de los mejores docentes que haya tenido en su historia: Rodolfo De Roux sale del país, amenazado y presionado, además de la derecha, por el mismo gremio de historiadores encabezado por la ilustre "Academia Colombiana de Historia", la cual confrontó de manera abierta su texto "Nuestra Historia". Este texto representó uno de los primeros ejercicios en observar una historia desde abajo, valorando las personas del común dentro de una visión de historia social, que desmitificaba la historia patria, heroica y tradicional que se enseñaba en las escuelas y colegios. Sin duda, el exilio del profesor Rodolfo De Roux, fue presionado por estas dos situaciones para posteriormente convertirse en uno de los mejores profesores de América Latina en las universidades europeas ${ }^{122}$.

La hegemonía de los dos grupos políticos: JUCO y MOIR en la Pedagógica fue la característica de la primera mitad de la década de los años ochenta. La Pedagógica contó con la presencia de cuadros nacionales, como Omer Calderón, representante estudiantil a finales de la década y a la vez Secretario General de la JUCO en el país, quien también hizo historia junto a su compañero William Agudelo, hoy dirigente de la $A_{D E}{ }^{123}$.

Para la segunda parte de la década de los años ochenta los grupos de trabajo estudiantil comienzan a distanciarse de los grupos políticos con tradicional hegemonía en la institución. La JUCO y el MOIR que, con grandes ideologías en cierta coyuntura, se mostraron como propuestas atractivas para las organizaciones entraron en un proceso de declive. Para estos años surgen otros grupos de trabajo académico y cultural que critican esta dinámica. Para ese entonces ya grupos como la Revista Clepsidra del departamento de Física encabezada por Juan Carlos Orozco, el grupo de Estudio Pedagógico (GEP), el Círculo de Pedagogía y Cultura (CPC), el Comité Estudiantil de Lenguas, el periódico Nuestras Palabras y el Comité Cultural de la UPN, expresaban la rica gama y diversidad en formas de organización y participación estudiantil alternas a las propuestas políticas.

\footnotetext{
${ }^{120}$ Ibid. p. 17.

${ }^{121}$ Ibid. p. 33 .

122 Rodolfo De Roux nació en Cali en 1945, es licenciado en Filosofía (Verese, Italia); licenciado y magíster en Teología (Universidad Javeriana de Bogotá); Doctor en Sociología de la Religión (Escuela de Altos Estudios en Ciencias Sociales en París); Doctor en Historia de América Latina (Universidad de Toluouse-Le Mirail). En su exilio en el año de 1992 de manera brillante en su carrera docente, la cual es una excepción entre latinoamericano alguno, alcanzó en la universidad europea el "everest" académico. Para ese año ganó el grado mediante concurso de profesor titular, recibiendo además la felicitación unánime de los cinco jurados que le otorgaron este estatus docente. (Ver Revista Hojas Universitarias de la Universidad Central, Bogotá, abril de 1999.)

${ }^{123}$ Estos líderes estudiantiles debido a su militancia afrontaron situaciones de riesgo que quedaron registradas en la prensa nacional. El 6 de diciembre de 1985 se dio un atentando con dinamita en la sede de la JUCO del centro de Bogotá en la que murió uno de sus militantes y salió ileso Omer Calderón, estudiante de Psicopedagogía de la UPN, quien fue detenido por los militares al siguiente día por encabezar una marcha de protesta $<$ Semanario Voz, 7 de diciembre de 1985). Por su parte William Agudelo, estudiante de Sociales de la UPN, fue detenido por desarrollar actividades políticas junto a la Unión Patriótica en Paz de Airoporo. Casanare (Semanario Voz, 15 de diciembre de 1986).
} 
En varios comunicados conjuntos estos grupos se dirigieron al entonces rector Francisco Cajiao, con el fin de comprometer a la administración de manera clara y abierta frente a la defensa de la universidad pública relacionada con las discusiones y los procesos de reforma interna ${ }^{124}$. La dinámica de estos grupos fue importante en la medida que organizaron grandes eventos de carácter académico. Aún se encuentran documentos del II y III Foro Distrital de Pedagogía, los cuales fueron liderados por estos grupos, de manera particular Clepsidra, grupo que logró comprometer no sólo a estudiantes sino a un importante grupo de profesores y académicos en torno a estas discusiones.

Otra muestra de independencia de los grupos de trabajo fue la presencia de Luis Ávila Morales, quien llegó al Consejo Superior en el período comprendido entre 1986 a 1988. Este líder estudiantil que posteriormente fue muy criticado, en uno de sus primeros comunicados dió a conocer que:

El pasado 27 de febrero (de 1987) se realizaron las elecciones estudiantiles convocadas por la universidad para escoger los representantes a los diferentes organismos de poden Los resultados revelaron claramente el triunfo de la propuesta del "Movimiento de Renovación Estudiantil" (MRE) y demostraron el querer del estudiantado de un cambio de estilo respecto a los dos últimos años de representación estudiantil, cuando la Juventud Comunista JUCO controló y manejó para su exclusivo beneficio político el asiento del Consejo, sin cumplir con la labor de informar periódicamente sus actividades para enfrentar en mejores condiciones la arbitraria política oficial contra la universidad pública ${ }^{125}$.

El nuevo representante pese a demostrar en una serie de continuos comunicados e informes donde enteraba a la comunidad universitaria de su labor y el tipo de discusiones que se daban en el Consejo, tuvo una mala intervención en los medios comunicación con respecto al informe de la Revista IDEAS en la que se señalaba a varios profesores de la institución como agentes del comunismo. En una entrevista televisada Luis Ávila reconoce que efectivamente hay comunismo en la universidad y varios de los implicados en ese informe profesan ideas comunistas. Su actitud no fue bien vista, originándose la reacción de la JUCO y de los sectores democráticos que comenzaron a criticarlo fuertemente en cada una de sus intervenciones.

La lectura que para esos años se hacía del movimiento estudiantil comenzaba a cambiar el panorama. Escuchemos a Daño Betancourt quien llegó como profesor catedrático en el año de 1988. En ese año este profesor comenzó a hacerle ver a los muchachos:

La necesidad del funcionamiento del movimiento estudiantil, pero mirándolo como una fracción de clase. Es decir entendiendo al estudiantado como un sector pluriclasista y no como la visión clásica de cierta izquierda mecanicista que lo veía como pequeña burguesía. Entonces la tesis que se sostenía era que el movimiento estudiantil era un sector policlasista; un sector cuya función esencial era estudiar, reivindicar la academia y que sólo desde la academia podía servirle a los intereses de las clases subalternas. Es decir desde el conocimiento de la estructura política, desde el conocimiento como funciona el Estado, como funciona la dependencia, como es el problema del imperialismo, bueno todos esos problemas. Esa es su contribución al movimiento popular y no al revés. La tesis de nosotros era: la izquierda lo que había hecho hasta ahora era el manoseo del movimiento estudiantil. Era mirar el cuadrito, sacárselo, llevárselo y tirarle tareas, vea diga esto, haga esto. El

\footnotetext{
${ }^{124}$ Documento. "Carta abierta de los grupos de trabajo", agosto de 1985, Archivo Centro de Documentación de Sociales UPN.

${ }^{125}$ Informe del representante estudiantil Luis Ávila Morales a la comunidad universitaria, 21 de abril de 1987. Archivo Centro de Documentación de Sociales UPN.
} 
movimiento estudiantil era pues "la puta" que toda la izquierda venía y se lo peleaba para manosearlo ${ }^{126}$.

Para Amadeo Clavijo, estos grupos políticos sólo entraban a participar de la dinámica estudiantil y de las movilizaciones, en coyunturas de elecciones para cargos de representación internos o para los procesos electorales en el ámbito nacional ${ }^{127}$. Es así como se consolidan una serie de grupos independientes que con diversas actividades culturales, académicas y también políticas, disputan el espacio jugado por las anteriores expresiones dadas más desde la militancia ${ }^{128}$. Varios grupos se consolidaron, pero tal vez el que más se destacó en la historia estudiantil de la Pedagógica Nacional en estos años fue el "Proyecto Cultural Alas de Xue" ${ }^{129}$. Este importante proyecto nació en el año de 1987 como grupo de trabajo estudiantil en el Departamento de Ciencias Sociales, y para inicios de los noventa tuvo una relevancia nacional e internacional siendo el principal grupo juvenil y estudiantil del país que se manifestó para la conmemoración del "Quinto Centenario del Descubrimiento de América".

Leamos a uno de sus creadores:

Todo comenzó en el año de 1987 en un encuentro estudiantil de Ciencias Sociales en Manizales. En él participamos gente de varios semestres. En una tienda charlábamos sobre lo que ocurría en la universidad y el desacuerdo de cierto sector de la dinámica de los grupos políticos de izquierda con peso tradicional. Nosotros como estudiantes independientes que nos sentíamos críticos de la realidad buscábamos otra forma de participación. En esa tarde hablamos del marxismo, de posiciones libertarias y hasta de la anarquía. Luego este grupo se cité aquí en la universidad y con ellos se comenzó a nuclear lo que sería Alas de Xue ${ }^{130}$.

En el grupo Alas de Xue se puede hablar al menos de tres etapas. La primera, su génesis, que se remonta a los años de 1987 al 1989, en la que se ubica la idea de organizarse como grupo de trabajo académico y cultural; el segundo, el periodo de 1989 a 1991 en el que definen los lineamientos académicos y políticos del grupo, optando por lo que ellos llamaron marxismo mágico y libertario ${ }^{131}$. En esta etapa se acercan a la Organización Indígena Nacional de Colombia (ONIC) con la cual encuentran cercanía cultural frente a la cosmovisión del mundo; y la tercera etapa, que se establece de 1991 a 1993 cuando ganan un reconocimiento nacional e internacional. Leamos a Amadeo:

\footnotetext{
${ }^{126}$ Entrevista con Darío Betancour, marzo de 1999. Estas declaraciones nacen de su experiencia como dirigente estudiantil en tres universidades: Pedagógica, Nacional y Libre. Esta visión del movimiento estudiantil, Darío la promulgó dentro de los dos talleres de estudio que lideró. El primero de ellos fue el "Taller Estudiantil Rescatemos" que tuvo presencia en la Pedagógica a finales del ochenta, y luego, el "Taller de Estudio la Culebra". En estos talleres Darío irradiaba entre sus integrantes el carácter académico que como grupo estudiantil los tenía que caracterizar, el estudio de temas específicos, coyunturas de cambios y el problema del Estado. Estos talleres fueron concebidos como espacios extra académicos donde varios de sus integrantes se cualificaron hasta llegar al punto que varios de ellos son profesores de varias universidades del país.

${ }^{127}$ Entrevista sostenida como Amadeo Clavijo Ramírez, mayo del año 2000. Este líder es uno de los fundadores del grupo libertario e indigenista Alas de Xue.

${ }^{128}$ Desde esta coyuntura se puede hablar al menos de tres tipos de participación estudiantil dentro de la realidad institucional. La primera de ellas es la Representación Estudiantil en las diferentes instancias como los Consejos de departamento, facultad, académico y superior; la segunda forma de participación, son los grupos eminentemente políticos como la JUCO, el MOIR, y el M-19; la tercera son los grupos de trabajo cultural y académico que tomaron una dinámica importante desde la segunda parte de los años ochenta hasta la primera parte de los noventa, entre ellos se encuentran: el grupo Rescatemos, el ¿Qué hacer hoy?; Alas de Xue, y entre otros el grupo Colectivo por la Vida que también fue importante, pues comenzó a trabajar desde esa época por la situación de derechos humanos en el país.

${ }^{129}$ De manera jocosa, los integrantes del grupo deciden el nombre de "Alas de Xue", que en lengua indígena Chibcha significa "Libertad del Sol". Nombre que se escogió sobre la otra alternativa "Atawa" que significa en Gayúu "Encuentro". Al no poder llegar al consenso se decidió de manera burguesa y votaron. Luego al calor de unas cervezas en Faro (sitio de moda para los niños Gomelos de la UPN) ratificaron el nombre de "Alas de Xue" sobre Atawa, segunda alternativa. Ver: Una historia de Anarquismo en Colombia: Crónicas de utopía. Colectivo Alas de Xue. Madrid- España. Madre Tierra Editores. 1999.

${ }^{130}$ Entrevista con Amadeo Clavijo Ramírez, mayo del 2000.

${ }^{131}$ En estas discusiones fue vital el papel de los entonces estudiantes Juan Carlos Gamboa, "Lucho” Fajardo y Amadeo Clavijo. 
En mi monografía de grado junto a Juan Carlos comenzamos a trabajar sobre la anarquía en los años 20, el origen del concepto, su relación con el marxismo, y la posibilidad de anteponer una nueva propuesta frente al marxismo ortodoxo. Se nos tildó de revisionistas, pero esta idea fue la que tomé fuerza en Alas de Xue. Se comenzó a hablar así de marxismo mágico y de un ideal libertario, el cual no nos distanció de la posibilidad de trabajar con las organizaciones indígenas, que también manejaban una visión del mundo desde la libertad. Por esta relación para los años de 1990-91 se nos contacta a nivel estudiantil para lo del Quinto Centenario del Descubrimiento. Después de una decisión interna aceptamos, canalizando todos esos recursos dados por el ICFES, para organizar un acto no en conmemoración sino en protesta por celebrar 500 años de genocidio cultural ${ }^{132}$.

Efectivamente Alas de Xue, antecedido de varios preencuentros nacionales, en junio de 1992 en las instalaciones de la Universidad Pedagógica, realiza el acto en protesta al genocidio cultural ocurrido hace cinco siglos. En el encuentro se valora más bien el aporte cultural aborigen y la resistencia indígena frente a la invasión ${ }^{133}$. En él participan un buen número de universidades del país y de delegaciones estudiantiles de Latinoamérica, las cuales comparten la visión del evento.

Alas de Xue, es visto como producto del proceso vivido en los años ochenta que dejó para la historia de la universidad al menos tres cosas importantes: la primera, la publicación de un libro como grupo de trabajo estudiantil titulado: Biofilo Panclasta el eterno prisionero, ${ }^{134}$ en el cual se hace un recorrido sobre el ideal anarquista en Colombia, dedicando vados apartes a un personaje peculiar, Vicente Lizcano, conocido como "Biofilo Panclasta" primer anarquista colombiano; lo segundo, pese a algunos altercados, la realización del evento ${ }^{135}$, convirtiéndose en la única expresión universitaria estudiantil del país y tal vez de las pocas de América que se pronunció sobre el Quinto Centenario; y tercero, el Manifiesto sobre 500 años de resistencia indígena, el cual salió del evento en el que se recoge la posición crítica de buena parte del estudiantado participante frente al genocidio indígena ${ }^{136 .}$.

\section{El Estudiantado de los años noventa. Un doble proceso}

En la década de los años noventa estudiantado de la Universidad Pedagógica, al igual que el del resto de las universidades públicas del país, empieza con una de las más

\footnotetext{
132 Ibid.

${ }^{133}$ Cercano a este tipo de deliberaciones el profesor Renán Vega, quien fue cercano a la vez de Mas de Xué por esos días lanza el texto: 12 de octubre ¿Descubrimiento o invasión? Bogotá CISF, 1991.
}

\footnotetext{
${ }^{134}$ Biófilo Panclasta el eterno prisionero. Bogotá Proyecto Cultural Alas de Xue 1992 Juan Carlos Gamboa, Amadeo Clavijo Ramírez. Luis A. Fajardo Sánchez, Renán Vega y Orlando Villanueva. Este texto ha sido valorado de manera positiva como un aporte a la producción sobre historia política en Colombia. (Mirar el balance de Historia Política de Medófilo Medina en: Historia al final del milenio, Bogotá. U.Nal, 1994). También la izquierda europea ha observado en este libro un aporte al estudio de la izquierda en América Latina, de manera particular la izquierda española.

${ }^{135}$ El 6 de junio de 1992 un grupo que se autodenominó anarquista quiso sabotear el evento quemando un bus frente ala Universidad Pedagógica, la cual tuvo que cerrarse en las horas de la tarde. El evento terminaría en instalaciones facilitadas por la ONIC.

${ }^{136}$ El carácter de protesta que tuvo el encuentro se logra percibir en varios apartes de los 14 puntos del manifiesto, publicado en Una historia de Anarquismo en Colombia: Crónicas de utopía. Colectivo Alas de Xue: "El Encuentro Nacional de Estudiantes 500 años reunido en sesión de trabajo asambleario en la Universidad Pedagógica Nacional de Colombia, en la ciudad de Bacatá los días 1 al 6 de junio de 1992, año 500 de la primera invasión declara: Que el 12 de octubre de 1492 se dió comienzo a uno de los más largos procesos de genocidio, etnocidio y ecocidio que la historia de la humanidad tenga noticia, y que aún no ha cesado. La pretensión de celebrar por parte de los centros imperiales y los gobiernos latinoamericanos el y Centenario, constituye un acto de arrogancia y desprecio frente a los habitantes del Tercer Mundo, que nos llena de indignación. Que el llamado nuevo orden internacional cumple medio milenio de destrucción y muerte. La violenta invasión de 1492 desencadené una serie de sucesivas invasiones, que han sido el común denominador de la historia de nuestros pueblos. Que detrás de las efemérides celebracionistas se esconden claros objetivos y propósitos económicos y políticos, aumentando la brecha entre los países ricos y los países empobrecidos, al imponerlas recetas y prédicas neoliberales en nuestro continente, que se caracterizan entre otras cosas por formas de democracia formal. Este hecho es evidente para los estudiantes con la puesta en marcha por parte del gobierno del Plan de Apertura Educativa, que representa un duro golpe para la democratización de la educación”. Pág 62-65.
} 
grandes crisis de desarticulación que ha vivido la historia del movimiento estudiantil. Si bien la Asamblea Nacional Constituyente, impulsada por la séptima papeleta con su posterior consecuencia política como lo fue la Constitución de 1991, fue un hecho que el sector gavirista del país abanderé como un proceso liderado por el estudiantado, se debe tener en cuenta que el estudiantado al que se hace referencia es al de las universidades privadas.

El estudiantado de las universidades públicas reaccionó tarde frente al proceso de reforma constitucional e institucional que se dió en el país en 1991. Al final del proceso, casi quede manera posterior a la definición de la constitución, un sector importante de las universidades públicas participaron del mismo, pero convocadas ya por el nuevo Estado que había dejado la reforma. En este proceso, que evidencia rezago del estudiantado, se debe recordar el Seminario Taller que se realizó en el edificio Alfonso López Pumarejo de la Universidad Nacional, en diciembre de 1991, bajo el titulo "La Juventud Colombiana y la Constitución de 1991", seminario en el que ya se había posesionado un Viceministro de la Juventud: Jimmy Viera, del sector de la Alianza Democrática M-19. Este seminario taller es bien particular porque participan los sectores de la izquierda tradicional universitaria, gritando consignas en "solidaridad con el pueblo cubano" y por "la vigencia y futuro del socialismo". La imagen que causaban estos sectores era de una incomprensión total frente a lo que se discutió en el seminario taller: la situación de la juventud frente a la constitución y los nuevos derechos que implicaba la reforma para este sector de la sociedad.

Las organizaciones estudiantiles de las universidades públicas empiezan con atraso su historia en la década de los noventa y, más bien, frente a la opinión pública se habla de un liderazgo político del sector privado. En el proceso de recuperar un movimiento estudiantil crítico, recogiendo las cenizas de su pasado, la Universidad Pedagógica jugó un papel importante en un inicio para después perderse del escenario, o participar muy tímidamente en el proceso de cohesión y movilización nacional. Las organizaciones estudiantiles comienzan de nuevo a pensar la posibilidad de crear una organización nacional dentro de la dinámica liderada por el grupo "Mas de Xue", en el marco de la celebración del quinto centenario del descubrimiento, realizado en el mes de junio de 1992 en la Universidad Pedagógica.

La anterior afirmación se da a conocer en el proceso que desemboca en la Asamblea Nacional de Estudiantes Universitarios (ANEU), proceso que toma fuerza hacía los años de 1993-1994, y del cual, años después nacería la ACEU. La ANEU en un documento de invitación a un Seminario Nacional de Liderazgo Estudiantil Universitario, celebrado en Manizales del 28 de septiembre al 1 de octubre de 1995, así lo da a conocer en algunos apartes donde manifiesta: "desde el Encuentro Nacional de Estudiantes 500 años, efectuado en la Universidad Pedagógica de Bogotá, en 1992, el Movimiento Estudiantil Universitario ha reanudado la marcha en el proceso de discusión, reflexión, participación y organización de los estudiantes colombianos. Posterior a este evento se han realizado otros encuentros de carácter nacional, el último de los cuales fue el Seminario Taller Nacional de Derechos Humanos, realizado, en Medellín los días 24 y 25 de junio de 1995, en cumplimiento de las decisiones de la Asamblea Nacional de Estudiantes Universitarios"137

\footnotetext{
${ }^{137}$ Documento de invitación al Seminario Nacional de Liderazgo Estudiantil Universitario y segunda reunión de la Mesa de Coordinación ANEU. Encuentro celebrado en Manizales del 28 de septiembre al 1 de octubre dc 1995. En este mismo documento se rechaza la muerte de los estudiantes: Norma Patricia Galeano de la universidad del Tolima, de Cesar García de la Universidad del Valle y de Humberto Peña Taylor (Duce) de la Universidad Nacional, ocurridos en ese año. P.2.
} 
Esta importante dinámica para la creación de un nuevo movimiento estudiantil colombiano está acompañada de otros encuentros y discusiones como la sostenida en la Universidad del Valle, donde se realizó un Consultivo Nacional Estudiantil, del 23 al 25 de febrero de 1994; luego la realización de un seminario taller "Hacia una visión crítica de la educación superior" realizado en la ESAP de Bogotá, del 25 al 27 de marzo del mismo año; y la realización del Seminario Nacional Universitario en Medellín del 16 al 18 de septiembre. ${ }^{138}$

En estos encuentros la preocupación central fue la de incentivar espacios de formación y cualificación de los estudiantes colombianos, como actores protagónicos del acontecer político, socio económico y cultural del país. Con estos eventos se buscaba superar en gran medida "las ausencias" de conocimiento e información acerca de la situación universitaria y del contexto socio-económico y político del país. El objetivo de la ANEU en su momento fue organizar un movimiento estudiantil gremialista que cohesionara a los estudiantes desde la academia, para que se reconocieran y se asumieran como actores protagónicos en los cambios del país. El objetivo de esta organización fue propiciar un espacio de encuentro y reflexión de los estudiantes universitarios colombianos de la universidad estatal-oficial y la universidad privada, en la perspectiva de formar universitarios integrales comprometidos con el futuro de la universidad y el país.

De esta manera, una de las principales preocupaciones de la ANEU fue la discusión de la política educativa gubernamental y las características del modelo educativo nacional. La Ley 30 de 1992, conocida como Ley de Educación Superior, fue discutida en un masivo encuentro de más de mil (1.000) estudiantes de las universidades públicas y privadas del país, realizado en la Universidad Nacional del 6 al I0de abril de 1995. En esta discusión una de las polémicas conclusiones fue tachar a la Ley 30 de 1992 como neoliberal. Los estudiantes en ese encuentro concebían la Constitución de 1991 como una constitución gavirista, aperturista y neoliberal. La Ley de Educación Superior, al responder a estos preceptos, acompañada de la Misión Ciencia y Tecnología de Gaviria, es tachada de neoliberal y privatizadora. Como es lógico una de las conclusiones del masivo encuentro fue el rechazo a la Ley de Educación Superior ${ }^{139}$.

Otra de las orientaciones de este encuentro fue convocar a una Jornada Nacional de protesta estudiantil para el 27 de abril de 1995, la cual en términos generales fue un fracaso. En una reunión de la mesa coordinadora nacional, realizada en la Universidad Distrital, de 17 delegaciones universitarias, doce reportaron no haber realizado la jornada nacional de protesta, entre ellas las universidades públicas de Bogotá: la Nacional, la Distrital y la Pedagógica. La única que reportó una actividad importante fue la universidad de Cartagena que realizó la jornada bajo dos criterios: difusión de las relatorías y conclusiones de la ANEU, y la denuncia de la crisis académica y financiera de la universidad. Por su parte la Pedagógica no efectúo ninguna actividad durante la jornada, pero ese día se realizó una ocupación pacífica del edificio administrativo por un grupo de estudiantes que exigía la derogatoria de la resolución del Consejo Superior que incrementaba ostensiblemente las matrículas ${ }^{140}$.

\footnotetext{
${ }^{138}$ Documento de invitación a la Asamblea Nacional Estudiantil, realizada en Bogotá, en la Universidad Nacional del 6 al 10 de abril de 1995. P.2.

${ }^{139}$ Lo particular es que años después, en el marco del Plan de Desarrollo del Andrés Pastrana (octubre de 1998 y primer semestre de 1999), la ya conformada ACEU hace una defensa abierta a la Ley 30, en la cual reconoce aún un carácter social y una garantía para el sostenimiento de la universidad pública. En esta defensa, caracterizada por marchas nacionales y movilizaciones de los estudiantes, fue fundamental el papel del rector de la Nacional Víctor Manuel Moncayo.

${ }^{140}$ Documento ANEU. Reunión de la Mesa Coordinadora Nacional. Conclusiones. Bogotá, Universidad Distrital, mayo 19 al 21 de 1995.
} 
Producto de este proceso, en el que se siguen realizando eventos locales, regionales y nacionales, es que en mayo de 1998 en el Congreso Nacional de Estudiantes Universitarios, realizado en la ciudad de Cartagena, liderado por la ANEU con participación de más de 90 instituciones de educación superior, privadas y públicas, se aprueba la conformación de la Asociación Colombiana de Estudiantes Universitarios (ACEU). Esta organización, producto de varios años de debate y de lucha del estudiantado, constituye una opción de participar organizada y propositivamente en los grandes debates y transformaciones sociales que el país necesita. Para las organizaciones y personas que lideran la ACEU, ésta es producto de un proceso gremial que se caracteriza por ser demócrata, pluralista, humanista y académico. ${ }^{141}$

Entre los objetivos trazados por la ACEU se establece buscar la unidad orgánica de los estudiantes universitarios en un contexto de autonomía universitaria; defender, construir y fortalecer el carácter estatal-público de las universidades establecidas como tales; luchar por criterios de calidad académica y cobertura de la educación superior en general y fomentar en el estudiantado la conciencia de la necesidad de la paz en el marco de la justicia social, con un real compromiso en la búsqueda de una solución al conflicto social y armado que vive la nación.

Para muchos el proceso de la ANEU y la ACEU ha sido liderado desde hace vados años por la Juventud Comunista Colombiana (JUCO) y por varios de sus cuadros que, como Alfredo Holguín, en ese entonces estudiante de Filosofía de la Nacional, buscan consolidar intereses políticos de partido. No en vano, además de puños y enfrentamientos físicos, este tipo de comentarios y pugnas se presentaron en la ciudad de Cartagena en 1998, particularmente en la mesa de trabajo en la que nació la ACEU. Para algunos el nacimiento de esta organización fue un "parto tortuoso" pero importante. En palabras de Holguín, pronunciadas en la Asamblea General de Cartagena en 1998, se debía aprovechar esa oportunidad histórica con más de 2.000 estudiantes de todo el país y con la participación de más de 90 universidades - públicas y privadas- para que esta organización política estudiantil —naciera de sus cenizas a nivel nacional.

En medio de estas polémicas se debe reconocer que esta organización es de gran importancia, pues la universidad pública busca un nuevo tipo de liderazgo y de legitimidad estudiantil que le permita ser tenida en cuenta como parte de la sociedad civil organizada en momentos coyunturales. La ACEU, como organización gremial y a la vez política, se conforma en un momento crítico de la vida nacional en el que el nuevo gobierno de Andrés Pastrana se aprestaba a iniciar un proceso de negociación con la guerrilla de las FARC-EP.

\section{El proceso interno en la UPN}

Si bien, este proceso de organización y robustecimiento se vive en el ámbito nacional, en la Universidad Pedagógica después del acto de 1992, el estudiantado como actor político comienza a vivir una fuerte crisis como colectivo. Se recuerda que para ese entonces las formas de protesta estudiantil en el ámbito nacional son criticadas y replanteadas. Eduardo Pizarro Leongómez, para el segundo semestre de 1991 hace una contundente crítica a "El tropel". Para este profesor, "El tropel" como manifestación de protesta no tiene ningún impacto social en la sociedad ni en el Estado. Más perjuicio le causa "El tropel" a la Secretaría de Trámite que al Ministerio de Defensa; "El tropel" es la expresión de un

\footnotetext{
${ }^{141}$ Documento ¿Qué es la ACEU y por qué marchamos? Mayo de 1999.
} 
sector minoritario de la universidad; además reviste una doble incomunicación: por un lado, de estos agentes de violencia hacia la comunidad externa; y, de otro, hay una extrema incomunicación hacía la comunidad interna. Por último, "El tropel" tiene rasgos totalitarios: expresa un profundo desprecio hacia la comunidad universitaria, que es percibida como un grupo de minusválidos mentales. Un minúsculo grupo de estudiantes iluminados se toma el derecho de indicarle a la comunidad universitaria lo que conviene pensar y oír, a quién puede escuchar y qué puede escuchar ${ }^{142}$.

Mientras tanto, en la Pedagógica, atrás habían quedado tiempos importantes del estudiantado en los años setenta o las manifestaciones intergremiales de la década de los ochenta. Al parecer la crisis de los paradigmas y de las utopías afectó profundamente sus formas de organización política. Grupos como el MOIR, la Unión Patriótica y el M- 19 perdieron fuerza de manera acelerada a comienzos de la década de los noventa. La JUCO, el grupo que más se mantuvo hizo presencia con un núcleo político e ideológico hasta el año de 1993, liderado por Orlando Misas, uno de los últimos cuadros de esta organización con presencia en la UPN. Posterior a ésto, los grupos de trabajo político se pierden completamente, al igual que los grupos de trabajo estudiantil importantes como Alas de Xue, Colectivo por la Vida y el taller de Historia la Culebra, estos como rezagos del anterior proceso, en el momento en que sus integrantes comienzan a graduarse.

Esta crisis política origina, de manera, directa un bajón en la calidad de los discursos y discusiones que se dan dentro del estudiantado. En los años noventa los estudiantes comienzan a enfrentarse por aspectos banales como la propiedad de las casetas de ventas de dulces o un espacio de la universidad para la venta de otros artículos. La crisis también se evidencia en la actitud del estudiantado ante el periódico estudiantil "El Eco", que desde el año de 1997 deja de circular. La razón de ésto, a pesar que desde la administración se garantizan los recursos para su edición, es que no hay estudiantes ni grupos de trabajo estudiantil que se preocupen por escribir.

Frente a este panorama, atrás quedaron, a finales de los años ochenta, una amplitud política de la discusión por parte de un estudiantado que era irreverente pero a la vez respetuoso de las diferentes expresiones políticas. A la Pedagógica llegaron los candidatos a la presidencia asesinados por el régimen y por las fuerzas oscuras del país: Jaime Pardo Leal, Bernardo Jaramillo, Carlos Pizarro Leongómez y el mismo Luis Carlos Galán, asistieron a la universidad, de manera paradójica, días antes a sus respectivos asesinatos, con el objetivo de discutir sus plataformas políticas. Los estudiantes escuchaban, polemizaban y discutían, pensando los problemas del país junto a una posibilidad política de cambio.

El año de 1992 es un punto de corte dentro de las formas de participación y organización estudiantil en la Pedagógica; de expresiones políticas y de grupos de trabajo estudiantil se pasa a la fuerza que toman grupos anarquistas alegando posiciones libertarias, no de carácter académico como las de Alas de Xue, es el caso de grupos que alegan la pedagogía de la acción como principal vía educativa para llegar al cambio social. Al parecer esta pedagogía de la acción demanda mayor compromiso del estudiantado frente a las acciones de hecho como los enfrentamientos directos con la policía, los mítines y tropeles. No en vano los estudiantes que organizaron el quinto centenario recuerdan que un grupo de estos quemó un bus frente a la Universidad Pedagógica, el 6 de junio de 1992, en momentos en que se cerraba el acto.

\footnotetext{
${ }^{142}$ El Tiempo, 22 de septiembre de 1991. Lecturas Dominicales, Pág. 8,9 y 10. "Cinco tesis sobre violencia en la Universidad", Eduardo Pizarro Leongómez.
} 
Luego de este hecho, este tipo de grupos fueron los que tomaron alguna fuerza utilizando como uno de sus símbolos de lucha: la capucha. Se debe anotar que la gran mayoría de comunidad universitaria no comprende este discurso, pues detrás de la pedagogía de la acción no existe una propuesta clara de universidad pública o una propuesta de cambio social, sino al parecer la propuesta se sintetiza en la acción y la resistencia.

En este sentido, la participación de algunos estudiantes de la Pedagógica en la conformación de la ANEU y posteriormente de la ACEU fue una iniciativa más personal y marginal que otra cosa. Mientras esto ocurría a nivel nacional, en nuestra institución se viví a una cotidianidad paradójica y anecdótica que queremos retener en estas páginas como un aporte a la memoria colectiva:

La tarde del viernes 15 de noviembre de 1991, la División de Bienestar Universitario organizó un gran concierto de música metal con tres grupos de reconocimiento nacional. Dentro de la memoria de los estudiantes de la época se recuerda que se habilitó el espacio de la canchas de básquet del sector de educación física que circunda con la piscina. Al acto que se inicio en las horas de la tarde asistió un gran número de personas, que hacían del ambiente de la universidad otro mundo. En pocas horas, la universidad se llenó de "metaleros" que con sus pintas estrafalarias se podían dividir en al menos dos grandes grupos: unos mechudos, vestidos de negro, con narigueras y grandes tatuajes pintados en su cuerpo; otros calvos, cabezi-rapados, y con botas de suela alta. Estos grupos, que eran los que en realidad venían a gozarse el concierto, sumaban unas 300 personas. A estos había que adicionarle un importante número de adolescentes y estudiantes del Instituto Pedagógico Nacional IPN; y claro, los estudiantes de la Pedagógica, que por derecho propio estaban dentro de las instalaciones. Bueno, los equipos se instalaron, los grupos llegaron y el escenario estaba a reventar para iniciar la "Pogueada". Los diferentes grupos escuchaban las canciones y bailaban (pogueaban). Sin embargo, su particular forma de hallar terminó en la agresión física. En determinado momento los estudiantes de la Pedagógica se retiraron de la pista y comenzó un enfrentamiento entre calvos y mechudos. Hasta ese momento los estudiantes optaron por asumir una neutralidad ante el enfrentamiento. Sin embargo, las cosas tendieron a agravarse cuando uno de los pogueadores rompió uno de los grandes vidrios que protege la piscina, mientras los oponentes sacaron un lavamanos y lo estrellaron al piso. En ese momento los estudiantes, que numéricamente eran más, se sintieron agredidos. Se recuerda que en ese entonces aún quedaba un importante sector de la JUCO, de Alas de Xue y de Colectivo por la Vida, quienes encabezaron la particular defensa de la universidad pública. Se inicia así una batalla campal utilizando "papas explosivas", piedras y palos. Con las primeras "papas" algunos de los mechudos y calvos se aturdieron, después vino la granizada de piedra y luego el enfrentamiento físico. Ese día el patio de la universidad, sus baños y corredores fueron escenario de la más grande batalla campal que se haya podido vivir en la Pedagógica. Los calvos y mechudos saltaban por la vallas y paredes de la universidad cual ratones en huida. Muchos fueron los heridos, ante todo los pogueadores, algunos con graves lesiones en su cabeza, otros con fracturas en sus huesos. En el grupo de heridos también entró un importante número de estudiantes del IPN. El orgullo inicial de los grupos de trabajo estudiantil universitario es que en este fuerte enfrentamiento en defensa de la universidad salieron ilesos.

Sin embargo, a los pocos días lo que les quedó fue la vergüenza pública en la universidad, hecho que originó el pronunciamiento de varias instancias entre ellas un grupo de estudiantes: 
"Donde quedan las libertades democráticas como la libertad de expresión, de los grupos de trabajo, quienes proponen un proyecto Político y Cultural Universitario basado en una autodeterminación que favorece a todos los sectores sociales y da posibilidad de participación. ¿Cuál derecho y respeto ala vida? Si utilizan los mismos mecanismos de represión estatal. Es que el rock nacional no tiene cabida en la universidad pública. Si estos movimientos y géneros hacen parte de nuestra realidad, de la juventud que serán alumnos nuestros en un futuro, si es que ya no lo son. Qué pasó con la tolerancia, con el pluralismo ideológico. Si estos grupos se rigen por esquemas retrógrados y dogmáticos, que se guían por su instinto de violencia sin antes escuchar, preguntar y dialogar"143.

Las diferentes críticas dadas después de los graves hechos ocurridos en la Pedagógica fue lo que caracterizó por aquellos días la "embarrada" de los grupos de trabajo. Este hecho también originó la reacción de otros grupos nuevos del Departamento de Sociales que, como Siry Langa (o campo abierto en lenguaje quechua), desarrollaron actividades de tolerancia cultural. Se hicieron varios conciertos de mezcla musical entre metal, rock, salsa, merengue, porro y carranguera. Pero sin la participación de los particulares invitados de ese día, que ni por la más amigable invitación volverían a la Pedagógica Nacional en un buen número de años.

Hacia el primer semestre de 1993 una pequeña oficina construida en madera en el primer piso del bloque $\mathrm{B}$, que en ese entonces funcionaba como oficina de estudiantes, explotó hacia las horas del medio día cuando un par de "compañeros" preparaban "papas químicas" para enfrentar a la Policía en un tropel. "Puertas y ventanas volaron a los lados y los dos combativos "compañeros" quedaron chamuscados por la pólvora, su color de piel era gris, no del susto sino por efecto de la misma y las gafas de uno de ellos colgaba de una de sus orejas. El otro yacía en el piso adolorido por las quemaduras y lesiones. La administración, en respuesta, cerró la oficina de estudiantes y como castigo se aplicó una serie de medidas de seguridad restrictivas. Se recogieron los escritorios, las máquinas de escribir y el papel, elementos con que la oficina estaba dotada. Estas medidas que en su momento causaron inconformismo duraron al menos el resto del semestre hasta que pasó la incertidumbre institucional.

Para ese entonces otro hecho paradójico fue la "torta marroquí", torta comestible hecha a base de marihuana, en la cual participaron en su elaboración algunos estudiantes y hasta funcionarios de la oficina de Bienestar Universitario; y que causó más de una docena de intoxicados, alteró el orden moral de la universidad y generó discusiones sobre el hecho en espacios como los consejos superiores. Algunos profesores de la vieja guardia dieron a conocer su alteración y traumatismo por esta mezcla alimenticia que expresaba extremos de adicción a la "bendita" hierba.

En estos años los tropeles han ido y venido en la Pedagógica, la gran mayoría de ellos sin responder a una dinámica estudiantil nacional. En alguna ocasión la protesta estudiantil buscó ser renovada; hacla el año de 1995 se recuerda la protesta desnuda de un grupo de estudiantes: hombres y mujeres del departamento de sociales que recorrieron la universidad "biringos", como "Dios los mandó al mundo", expresando un nuevo tipo de protesta frente a las directivas y sus compañeros. Sin embargo, algunos de los espectadores manifestaron su pesar al ver que una mujer de 20 años tuviera tan excesiva celulitis, como la que se observaba en el cuerpo de una de las compañeras, que cometieron la osadía. En general una mezcla de cotidianidad y de inconformismo estudiantil se ha dado en los últimos años en la universidad.

\footnotetext{
${ }^{143}$ Comunicado ¿Cuál Libertad de expresión? Grupo de estudiantes UPN. 18 de noviembre de 1991. Centro de Documentación del Departamento de Sociales.
} 
Otro hecho fue la celebración de los 30 años de la muerte de Ernesto Guevara de la Serna, el Comandante "Che" Guevara (1928-1967). Para esta fecha, octubre de 1997, en la Universidad Pedagógica, un grupo de estudiantes decide colocar un busto del revolucionario latinoamericano, en el mismo lugar donde se había colocado a finales de la década del sesenta el busto de Santa Teresa de Ávila; en el mismo lugar donde luego se colocó la placa de Camilo Torres; y sobre el que pronunciaron sus primeros discursos décadas atrás Socorro Ramírez, Juvenal Nieves, Abel Rodríguez y el mismo Darío Betancourt, junto a los líderes de la década del ochenta.

Estos estudiantes tal vez pensaron que con algún atraso cronológico le tenía que tocar el turno en el patio de la solidaridad al Che Guevara, treinta años después. El busto fue colocado en un acto pomposo acompañado de un video latinoamericanista. Lo grave fue que el busto no duró ni siquiera una semana. Herederos de la intransigencia y de lo que Rodolfo De Roux, años atrás denominó lo sagrado al acecho, le rompieron la insigne boina al combativo revolucionario. El pequeño muro que aún se encuentra en el centro del patio de la solidaridad siempre lite un punto en el que los estudiantes buscaron sembrar identidad, cohesión social y política como miembros pedagógicos hasta ese momento. Luego de este acto otro grupo de estudiantes colocó una figura virtual que a nadie afecta la cual se ha mantenido desde entonces. El patio de la solidaridad hoy en día ha dejado de existir, pues le ha crecido hierba, maleza y árboles, que impiden la reunión de los estudiantes. En la actualidad, es el espacio preferido para los estudiantes con el fin de descansar o lo que ellos llaman "pastar".

Uno de los Últimos hechos que alcanzó a sintetizar con buena pluma el profesor Darío Betancourt y que expresa esta mezcla de cotidianidad e inconformismo estudiantil, fue lo ocurrido el 8 de marzo de 1999, día internacional de la mujer. El profesor de manera jocosa tituló un volante: "El 8 de marzo de 1999, día internacional de la mujer. Entre el mariachi, la capucha y la rosa en la UPN".

A pesar de lo apacible, monótono, tedioso y pesado que a veces se nos toma el transcurrir cotidiano en la Universidad Pedagógica, en su entorno colectivo, en los espacios de socialización y de esparcimiento, acontecen ciertos hechos, que no pueden pasar desapercibidos en aras de construir una memoria colectiva, una memoria histórica que alimente tanto el presente como el futuro. En efecto, el soleado lunes ocho de marzo, mientras los estudiantes departían en la Plaza de la Solidaridad en fa UPN y esperaban la actividades que Bienestar Universitario había programado para dicha conmemoración, por el parqueadero de la calle 72 , a las 12:45, se hizo presente un micro bus con un grupo de "mariachis" vestidos de negro, con charreteras, grandes sombreros y guitarrones; uno de los integrantes de tan vistoso elenco, se dirigió a la cafetería y buscó a una estudiante de la universidad, al parecer, su esposa y se encaminó hacía el parqueadero de la calle 72 . Un grupo de estudiantes, que se encontraba en "el aeropuerto", sorprendidos sólo atinan en lanzar unos cuantos chiflidos, pero se quedaron un poco perplejos ante la rara presencia de un mariachi a medio día en la universidad.

En la entrada de la calle 72, en pleno parqueadero y mientas el grupo de "mariachis" afinaba sus instrumentos, el mariachi enamorado, esposo de la estudiante, leía y hacía entrega de un manifiesto de amor de unas tres cuartillas a su amada; un nutrido grupo de estudiantes que ya se había agolpado en rededor aplaudía y festejaba a los enamorados sin vislumbrar todavía su angustia y su tragedia. La estudiante "festejada". en la mitad del redondel espontáneamente formado rasgó la misiva de amor, desesperada y en gesto de desaprobación se paró en actitud retante con el ceño fruncido y la mirada inyectada frente al enamorado y demás integrantes del mariachi que para entonces ya entonaba canciones rancheras. Al parecer la estudiante no sólo estaba furiosa por los penosos y reiterados agravios de su marido sino por "el oso" ante sus compañeros y ante la universidad. El 
mariachi, moviéndose en otra lógica, en la de los "meros machos", no entendía por qué su mujer, no sólo no acepaba su desagravio, sino le disgustaba semejante acto de amor desesperado; entre otras cosas esta era la actitud que parecía desprenderse de comentarios de las estudiantes, que para entonces coreaban a los mariachis, reían, gritaban y pedían un besito de parte de la estudiante "festejada".

Mientas tanto, por la calle 73 hizo presencia un grupo de unos 5 o 6 encapuchados también vestidos de negro y portando rosas rojas, blancas y amarillas; realizaron una arenga alusiva al día internacional de la mujer frente a la cafetería ante un nutrido grupo de estudiantes; después de leer y repartir un manifiesto, entregar rosas a las compañeras estudiantes presentes y expresar que detrás de la capucha habían estudiantes cotidianos que amaban y luchaban diariamente, que tenían necesidades, que tenían corazón y que con este acto homenajeaban a la mujer luchadora de Colombia, salieron hacia la calle 72 a realizar "un tropel", pero se encontraron con otro grupo de estudiantes que rodeaba a los mariachis, y que celebraban sin pensarlo el día de la mujer, de la mujer real de aquí y de ahora, de la mujer colombiana, de la misma que sufre, lucha, ríe y se enamora; el grupo de estudiantes que rodeaba y coreaba a los mariachis, chiflaron a los encapuchados y se opusieron al tropel, pues este no podía romper tan sublime y espontáneo acto de amor, de tragedia y de comedia; hasta el punto que uno de los miembros del grupo de encapuchados al parecer entendió la situación y ordenó la retirada, soltando en pleno patio de la solidaridad, cerca del edifico B un estruendoso tote, "para no perder el impulso".

Pero en el grupo de estudiantes y el mariachi enamorado la cosa se complicaba, pues entró en escena una tía de la esposa agraviada-desagraviada, quien tomó a golpes al mariachi, rompiéndole la nariz ante los gritos de aprobación y reprobación de los estudiantes. El mariachi enamorado, el representante de los "meros machos" batió retirada, sollozando y sangrante, mientras que el grupo de mariachis terminó entonando canciones para los estudiantes.

Entretanto, en otro espacio de la universidad, el grupo de los encapuchados vestidos de negro, plegaban sus capuchas y retornaban a la cotidianidad de la tarde del lunes en la UPN, unos y otros hablan celebrado el 8 de marzo, El Día Internacional de la Mujer: Los primeros a través de la tragicomedia violenta que viven día a día muchas parejas colombianas, los segundos con el homenaje como acto simbólico a la mujer luchadora. Lastima que, mientas los primero rasgaban su careta (como el payaso que tiene el alma rota), los segundos hasta para homenajear a la mujer tuvieran que ponerse una máscara ${ }^{144}$.

Con este escrito de carácter anecdótico termina la reflexión acerca del estudiantado de la Pedagógica en diferentes coyunturas históricas. Este último período, tal vez es en el que más existe distanciamiento de este importante actor social con la realidad y las discusiones de tipo nacional, es decir, no sólo se vive un distanciamiento con el movimiento estudiantil nacional sino con las mismas dificultades políticas por las que atraviesa el país. Si bien Francisco Leal Buitrago habló de "la frustración de una generación para los años sesenta", pues ni se hizo la revolución ni se modernizó el país, en la década de los años noventa la juventud y el estudiantado siguen debiéndole a la nación al menos la segunda tarea: un mayor aporte a la democratización y a la modernización de la universidad y del país, basado en la fuerza de la academia.

\footnotetext{
${ }^{144}$ Darío Betancourt, "El 8 de marzo, día internacional de la mujer. Entre el mariachi, la capucha y la rosa en la UPN”, publicado en marzo de 1999.
} 